\title{
Vibration of Slender Structures Subjected to Axial Flow or Axially Towed in Quiescent Fluid
}

\author{
L. Wang and Q. Ni \\ Department of Mechanics, Huazhong University of Science and Technology, Wuhan 430074, China \\ Correspondence should be addressed to L. Wang, wanglinfliping@sohu.com
}

Received 9 November 2008; Accepted 16 April 2009

Recommended by Rama Bhat

\begin{abstract}
The vibrations and stability of slender structures subjected to axial flow or axially towed in quiescent fluid are discussed in this paper. A selective review of the research undertaken on it is presented. It is endeavoured to show that slender structures subjected to axial flow or axially towed in quiescent fluid are capable of displaying rich dynamical behavior. The basic dynamics of straight and curved pipes conveying fluid (with or without motion constraints), carbon nanotubes conveying fluid, tubular beams subjected to both internal and external flows in axial direction, slender structures in axial flow or axially towed in quiescent fluid, cylindrical shells conveying or immersed in axial flow, solitary plate or parallel-plate assembly in axial flow; linear, nonlinear, and chaotic dynamics; these and many more are some of the aspects of the problem considered.
\end{abstract}

Copyright (C) 2009 L. Wang and Q. Ni. This is an open access article distributed under the Creative Commons Attribution License, which permits unrestricted use, distribution, and reproduction in any medium, provided the original work is properly cited.

\section{Introduction}

The study of flow-induced vibrations of slender structures has been intensified in the past decades. This may be partly due to the increased need for stability and reliability, especially in the power generating industry where repeated equipment failures have evidenced the inadequate state-ofthe-art. Thus, it has now become increasingly important to try to understand and to be able to predict the dynamical behaviour of slender structures in flow, such as what might be found in mechanical equipments, nuclear reactors, heat exchangers, steam generators, ocean mining pipes and drill-strings [1-3]. Unlike the case of vibrations of slender structures induced by cross-flow, the study of dynamical behaviours of such structures induced by axial flow is a relatively new phenomenon, beginning seriously in the 1960s [4, 5]. Although most failures are associated with the cases of cross-flow, the conditions of axial flow have also been shown to be of importance. Moreover, quite apart from practical considerations, these problems are of sufficient intrinsic interest, in the realm of dynamics of various dynamical systems subjected to gyroscopic forces (e.g., axially accelerating belts), to merit study for their own sake.
Motivated by the quest for a fundamental understanding of fluid-structure interactions as well as by applications in several areas of engineering, the vibrations of axially moving slender beams or cylinders in fluid has also attracted the attention of several investigators [6-8]. As can be expected, the dynamics of slender structures axially towed in fluid should be different from that of slender structures conveying fluid or immersed in axial flows.

The current paper attempts to present a selective review of the published literature, emphasizing the work dealing with slender structures subjected to axial flow or axially towed in fluid, specifically the vibrations and stabilities of (i) pipes conveying fluid, both straight and curved (ii) carbon nanotubes conveying fluid (iii) tubular beams subjected both internal and external axial flows (iv) cylindrical shells conveying fluid (v) plates in axial flow and (vi) slender structures axially towed in quiescent fluid. The main purpose of this article is to review the recent literature which is relevant to all aspects and ramifications of slender structures subjected to axial flow or axially towed in fluid. In order to display some new results reported on this problem, the related background theory and some of the early work will also be discussed. 


\section{Dynamics of Straight Pipes Conveying Fluid}

Since the dynamics of straight and curved pipes, cantilevered and supported pipes, are fundamentally different, they will be treated separately. In each case the linear dynamics will be treated first.

\subsection{Linear Dynamics of Straight Pipes Conveying Fluid}

2.1.1. The Simplest Equation of Motion. Consider a straight pipe conveying fluid (Figure 1). If externally imposed tension, internal damping, gravity, a possible elastic foundation and pressurization effects are either neglected or absent, the linear equation of motion can be written in a particularly simple form [9]

$$
E I \frac{\partial^{4} w}{\partial x^{4}}+M U^{2} \frac{\partial^{2} w}{\partial x^{2}}+2 M U \frac{\partial^{2} w}{\partial x \partial t}+(M+m) \frac{\partial^{2} w}{\partial t^{2}}=0,
$$

where $E I$ is the effective flexural rigidity of the pipe, $m$ is the mass of the pipe per unit length, $M$ is the mass of fluid per unit length, flowing with a steady flow velocity $U$, and $w$ is the lateral deflection of the pipe; $x$ and $t$ are the axial coordinate and time, respectively. The fluid forces are modeled in terms of a plug flow model, which is the simplest possible form of the equation of motion for straight pipes conveying fluid. A more detailed treatment of the linear equation of motion was given in [9].

The various terms in (1) may be defined, sequentially, as the flexural restoring force, a centrifugal force, a Coriolis force, and the inertia force.

2.1.2. Straight Pipes with Supported Ends. The linear dynamics of the system for a pipe simply supported at both ends is very clear now. After a Galerkin discretization, the equation of motion, as given by (1), can be solved by considering a characteristic eigenvalue problem. The eigenfrequencies (denoted by $\omega$ in this paper) of the pipe system are generally complex. For the sake of convenience, we may define $\bar{U}$ as the dimensionless flow velocity, that is, $\bar{U}=(M / E I)^{1 / 2} L U$. Note that $\operatorname{Re}(\omega)$ is the oscillation frequency, while $\operatorname{Im}(\omega)$ is related to the damping, the damping ratio being $\operatorname{Im}(\omega) / \operatorname{Re}(\omega)$. It has been found that divergence in the first mode occurs at $\bar{U}_{c}=\pi$ and in the second at $\bar{U}_{c}=2 \pi$. Linear theory predicts a coupled-mode flutter for $\bar{U}>6.375$.

In [9], a similar result was obtained for a clampedclamped pipe. In this case, the first-mode divergence occurs at $\bar{U}_{c}=2 \pi$; then the system is restabilized at $\bar{U} \approx 9$. Again, still according to linear theory, another form of postdivergence (coupled-mode) flutter was predicted at $\bar{U} \approx$ 9.3.

However, the physical existence of this postdivergence flutter instability is questionable, since the linear equation of motion cannot be used to provide reliable information once the displacements become large. Therefore, this postdivergence flutter would have to be verified by nonlinear theory, as will be discussed later.

2.1.3. Straight Pipes with Clamped-Free Ends. Unlike the straight pipes with both ends supported, the linear dynamics

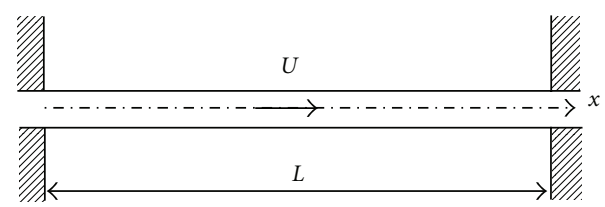

FIGURE 1: Schematic of a fluid-conveying straight pipe with both ends supported.

for a cantilevered system may show significant difference [10]. Up to now, it has been reported that the effect of increasing $\bar{U}$, provided it remains small, is to generate flowinduced damping in the system. For a relatively small flow velocity, it was shown that the value of $\operatorname{Im}(\omega)$ remains positive. For increasing values of $\bar{U}$ (e.g., $\bar{U} \approx 4$ ), however, this damping begins to be attenuated. The damping eventually vanishes (at $\bar{U} \approx 5.6$ ) and then becomes negative. This implies that a single-degree-of-freedom (DOF) flutter via a Hopf bifurcation occurs. The presence of nonzero damping at $\bar{U}=5.6$, therefore, merely postpones the onset of flutter.

In the last two decades, a vertically cantilevered pipe conveying fluid upwards was also studied by several investigators [11-14]. It ought to be recalled that this problem is not wholly academic. One important application may be in the ocean mining industry. The ocean mining of manganese nodules, by essentially vacuuming the sea floor from a surface vessel, thus involves a flexible, long pipe. In this case, the vertical pipe is always aspirating fluid; thus, the dynamics may be different from that of the system conveying fluid downwards, as discussed in the foregoing.

Up to now, in several experiments, it was observed that a fluid-aspirating pipe is stable for small flow velocity. However, theoretical results [14] have shown that flutter might occur even for pipes aspirating fluid with sufficiently low-flow velocity. In 2005, a reappraisal of why aspirating pipes do not flutter at infinitesimal flow is made by Païdoussis et al. [14]. In that paper, the linear equation of motion of a cantilevered pipe aspirating fluid was written as

$$
\begin{aligned}
& E I\left(1+\alpha^{*} \frac{\partial}{\partial t}\right) \frac{\partial^{4} w}{\partial x^{4}}+\left[M U^{2}-(\bar{T}-\bar{p} A)\right] \frac{\partial^{2} w}{\partial x^{2}} \\
& +2 M U \frac{\partial^{2} w}{\partial x \partial t}+c \frac{\partial w}{\partial t}+\left(M+m+M_{a}\right) \frac{\partial^{2} w}{\partial t^{2}}=0
\end{aligned}
$$

in which the added mass per unit length $M_{a}$ of the ambient fluid has been included; $c$ is the viscous damping coefficient, $A$ is the cross-section-area of the fluid, $\alpha^{*}$ is the coefficient of Kelvin-Voigt internal dissipation, $\bar{p}$ is the global pressurization, and $\bar{T}$ the externally imposed tension.

From (2), if the dissipation is absent or neglected, it can be easily verified that instability is possible for small internal flow velocity. If, however, a realistic amount of dissipation is taken into account, the straight pipe was found to remain stable up to flow velocities covering the range of practical interest (for the ocean mining application, e.g.). Thus, it has now become imperative to try to understand the stability mechanism of pipes aspirating fluid. However, this question remains unresolved. In [14], it has been suggested that 
more precise assumptions made on the intake flow structure should be developed in the near future. Was the observed stability only due to dissipation? Or was it because the flow at the intake is such as to make flutter impossible? To help get to the bottom of things, a CFD study of the flow field would be helpful, as mentioned in [14].

\subsection{Nonlinear Dynamics of Straight Pipes Conveying Fluid}

2.2.1. Straight Pipes with Supported Ends. Presuming the existence of periodic motions, the rate of work done by the fluid on the pipe over a period of oscillation $T$ may be obtained from (1) [13]

$$
\Delta W=-\left.M U \int_{0}^{T}\left[\left(\frac{\partial w}{\partial t}\right)^{2}+U\left(\frac{\partial w}{\partial t}\right)\left(\frac{\partial w}{\partial x}\right)\right]\right|_{0} ^{\mathrm{L}} \mathrm{d} t .
$$

Clearly, if both ends of the straight pipe are positively supported, then $(\partial w / \partial t)=0$ at both ends, and

$$
\Delta W=0 .
$$

This implies that self-excited oscillatory motion (flutter) is not possible for pipes with both ends supported. However, this does not mean that the system remains stable even for sufficiently high $U$. The $+M U^{2}\left(\partial^{2} w / \partial x^{2}\right)$ term can be viewed as an effective compression associated with the exiting fluid momentum at the downstream end. This might be linked to a slender column subjected to a compressive force. For high enough $U$, therefore, the system would lose stability by buckling (static divergence).

In fact, even in the context of linear theory, the existence of flutter is problematic for a pipe with positively supported ends. This delicate question was first addressed by Done and Simpson [15]. The question of the existence of postdivergence flutter (coupled-flutter) in this system has been answered by Holmes and his coworker [16-18]. Reference [17] is categorically entitled "Pipes supported at both ends cannot flutter"-for pipes positively supported at both ends, that is, where axial sliding is not permitted. Obviously, this important conclusion was based on analyzing the nonlinear dynamics of fluidelastic systems.

All the work mentioned in the last paragraph relates to theoretical work. In fact, the postdivergence flutter has never been observed experimentally in pipes with both ends supported, though the loss of stability by divergence is easily observable. Perhaps this is the most potent evidence of nonoccurrence of postdivergence flutter in pipes with both ends supported.

Moreover, parametric resonances may occur if the flow in the pipe is not wholly steady but contains periodic pulsations. Recently, quasiperiodic and chaotic motions were detected in pipes conveying fluid with both ends supported; see, for example, $[19,20]$.

2.2.2. Straight Pipes with Clamped-Free Ends. For a cantilevered pipe system, it is assumed that the free-end is at $x=L$. Then, one obtains [13]

$$
\Delta W=-\left.M U \int_{0}^{T}\left[\left(\frac{\partial w}{\partial t}\right)^{2}+U\left(\frac{\partial w}{\partial t}\right)\left(\frac{\partial w}{\partial x}\right)\right]\right|_{0} ^{L} \mathrm{~d} t \neq 0 .
$$

By analyzing the above equation, it is clear that $\Delta W<0$ for $U>0$ and small, and free motions of the pipe are damped. If, however, $U$ is sufficiently high, while over most of the cycle $(\partial w / \partial x)_{L}$ and $(\partial w / \partial t)_{L}$ have opposite signs, then one can obtain $\Delta W>0$. This implies that the pipe will gain energy from the flowing fluid, and hence free motions will be amplified.

The nonlinear dynamics of straight pipes with clampedfree ends is concordant. If we denote the onset of flutter as a Hopf bifurcation, the Hopf bifurcation gives rise to limit cycle motions, which is also what is observed experimentally. In this case, however, the dynamics can be much more complex. The Hopf bifurcation can be either supercritical or subcritical, depending on the parameter of mass ratio $\beta(=M /(M+m))$ and a parameter involving the friction coefficient and the slenderness of the pipe [21]. Moreover, the limit cycle motion can be either two or three dimensional [22], again depending on $\beta$.

The chaotic dynamics of cantilevered systems was also investigated extensively in the past two decades (see, e.g., [23-32]). In the first such study, Tang and Dowell [23] considered a cantilevered pipe with an inset steel strip and two equispaced permanent magnets on either side of the freeend, thus exerting nonlinear forces on the strip and buckling it into one of the two potential wells on either side of the pipe. If the flow velocity is increased sufficiently above the critical value for flutter about the buckled state, numerical results will show that the cantilevered system might display chaotic motions. This autonomous system was studied only briefly and theoretically. A more extensive theoretical and experimental study was made of a pipe system with external excitation. In the experiments, the pipe was excited by a shaker. Once again, chaotic motions were detected when the amplitude of the external excitation was sufficiently higher than the threshold value of this force for chaos. The chaotic motions, strongly influenced by the flow velocity, have also been observed experimentally.

At about the same time, Païdoussis and Moon [24] undertook a combined theoretical and experimental study of the autonomous system of a cantilevered pipe conveying fluid. In this case, however, the pipe is interacting with motion constraints somewhere along the length of the pipe. The only nonlinearity considered in the system was due to the nonlinear constraints, modeled by cubic springs. The experiments for a cantilevered pipe, with either air or water internal flow, showed that, when the flow velocity was sufficiently beyond the onset of flutter for the pipe, the pipe would impact on the motion constraints, thus introducing nonlinear force. The system became chaotic through the route of period doubling bifurcations. The analytical model, after Galerkin discretization to two DOFs., exhibited a similar behaviour. The same analytical model was further studied and some new results were obtained by Païdoussis et al. [25]. It was shown that, after the Hopf bifurcation, a symmetry-breaking transcritical-like pitchfork bifurcation occurs, followed by a sequence of perioddoubling bifurcations, leading to chaotic motions. Sample results of phase portraits based on the equation of motion given in [25] are shown in Figure 2. 
This same system was restudied with higher dimensional models (up to 7 d.o.f.) by Païdoussis et al. [26]. More significantly, the impact models for the motion constraints were improved. In this case, for the exact experimental parameters in the analytical model, excellent quantitative agreement (within 5-10\%) was obtained.

Finally, by using the full nonlinear equations of motion [27], the same cantilevered system was re-examined, completing the circle of studies on this system. The post-Hopf dynamics predicted with lower d.o.f. (e.g., 3 d.o.f.) was quite different from that predicted with higher d.o.f (e.g., 4 d.o.f.). It was found that, the degree of agreement with experiment becomes excellent for at least 4 d.o.f..

Also, if the cantilevered system is standing, interesting dynamics (e.g., the pipe regains stability after flutter instability as the flow velocity is increased) may arise [28, 29]. However, in the study of [29], the only nonlinearity considered is the nonlinear force induced by the motion constraints.

Moreover, chaotic motions may also occur for a cantilevered system with an intermediate linear spring support, or with a mass added at the free-end [30-32]. In [31, $32]$, the pipe is allowed to vibrate in a $3 \mathrm{D}$ space. The intermediate spring supports were disposed in symmetrical fashion with respect to two axes. For the pipe with a fourspring array placed somewhere along the length of the pipe (but not close to the free-end), it was found that the system loses stability via a Hopf bifurcation (i.e., similarly to the planar motion of a cantilevered pipe). Again, a pitchfork, or symmetry breaking bifurcation was detected at a higher flow velocity. However, the pipe was predicted to oscillate asymmetrically; and symmetry is regained for a higher flow velocity. Interestingly, quasiperiodic oscillations, followed by chaotic oscillations, have been found in such a dynamical system with sufficiently high-flow velocity. However, if the array of four springs is positioned closer to the free-end and the total stiffness of the springs is much larger, the initial instability was predicted to be a pitchfork bifurcation.

\section{Dynamics Of Curved Pipes Conveying Fluid}

One might have thought that a similar analysis of straight pipes conveying fluid can be extended to curved pipes. This is not so, however. Actually, in contrast to the systems reported so far, until 1988, there remained considerable confusion and uncertainty as to the vibrations and stability of curved pipes conveying fluid.

Work on the vibration and stability of curved pipes conveying fluid appears to have started in the 1960s. Some of the key contributions in this realm were made by, but not limited to, Svetlitskii [33-35], Chen [36-38], Doll and Mote Jr. [39, 40], Hill and Davis [41], Dupuis and Rousselet [42], Misra et al. [43-45], Ni et al. [46], Qiao et al. [47, 48], and Jung and Chung [49]. The systems studied range from curved pipes shaped as circular arcs, L- or S-shaped configurations, analyzed by finite-element techniques [3941, 43-45], transfer-matrix technique $[42,50]$ or differential quadrature method (DQM) [46-48, 51, 52].

Unlike the straight pipes, motions of curved pipes generally require four displacement variables (three displacements of the centerline and a twist angle) and hence at least four equations to govern the motions. For the circular-centerline pipes, depending on the initial shape and state of the system as well as assumptions made, it is often possible to decouple the motions into in-plane and out-of-plane motions.

There are three main theories available for predicting the stability and vibrations of curved pipes conveying fluid: the so-called "inextensible theories" [36, 37, 43, 46-48], the modified inextensible theory [44], and the complete "extensible" theories [33, 34, 40-42, 44, 45, 49]. The inextensible theories assume that the circular centerline of the pipe is essentially inextensible and all steady-state stress resultants are absent or neglected. The complete extensible theories, however, do not make this assumption and generally take into account the changes in form with increasing flow velocity, as well as the forces generated thereby; thus, the steady-state axial tension-pressure force has been considered. The modified inextensible theories take into account the initial stresses due to flowing fluid in a curved pipe.

The inextensible theories predict that curved pipes with both ends supported are subject to divergence at sufficiently high-flow velocities, similar to straight pipes. However, instability was predicted to be impossible by using the modified inextensible and the extensible theories. One interesting practical result is that the modified inextensible theory gives results very close to those of the complete extensible theory. For the cantilevered system, however, both the inextensible and extensible theories predict that the form of flutter instability might occur with sufficiently highflow velocity. The reason may be that the steady-state axial tension-pressure force has a less pronounced effect on the dynamics of cantilever system [48].

Here, it should be pointed out that, the literature on the nonlinear dynamics of curved pipes conveying fluid is very limited. Dupuis and Rousselet [53] have undertaken a careful derivation of the nonlinear equations of motion by the Newtonian approach; however, their equations are not easy to solve because of their complexity. In 2005, by using the inextensible theory, $\mathrm{Ni}$ et al. [46] developed a cantilever model, in which a curved pipe is embedded in nonlinear foundations. Based on DQM discretization, the in-plane vibrations of the system were discussed, showing that chaotic transients could occur. Recently, Qiao et al. [47] investigated another cantilevered curved pipe conveying fluid with motion constraints (Figure 3) and explored some interesting dynamics. Again, the inextensible theory was utilized for the cantilevered system. As can be expected, the curved pipe would impact on the motion constraints when the deflection of the pipe becomes reasonably large due to increasing fluid velocity. The analytical model, after DQM discretization, exhibited various behaviors (see Figure 4). The route to chaos was shown to be via period-double bifurcations. This curved pipe model was further analyzed by Lin et al. [48] by applying an external excitation at the free-end of the curved pipe. In the forced pipe system, the routes to chaos were found to be via either period-double bifurcations or quasiperiodic motions. Therefore, the forced system can also display rich dynamics. 


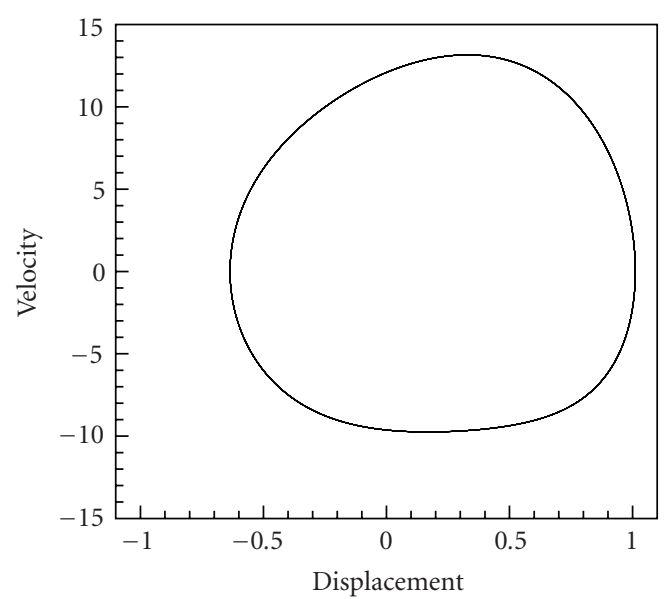

(a)

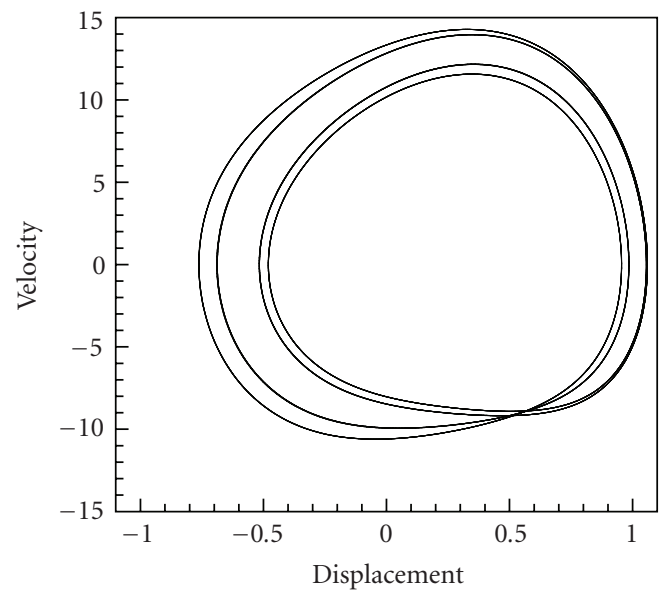

(c)

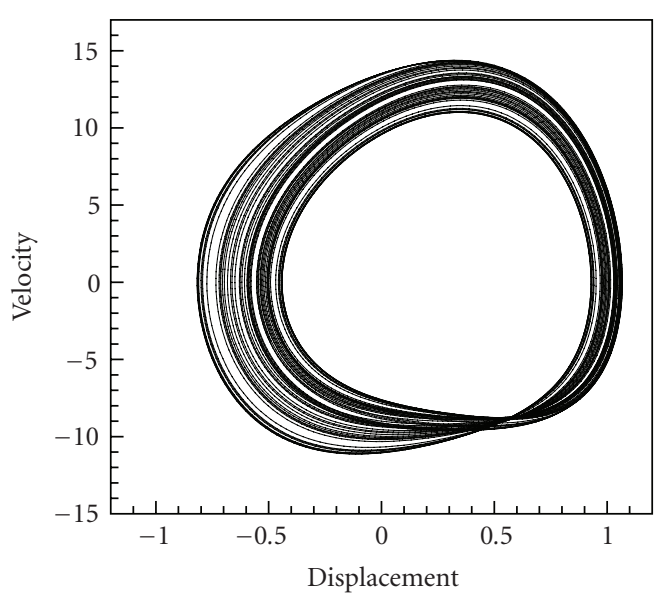

(e)

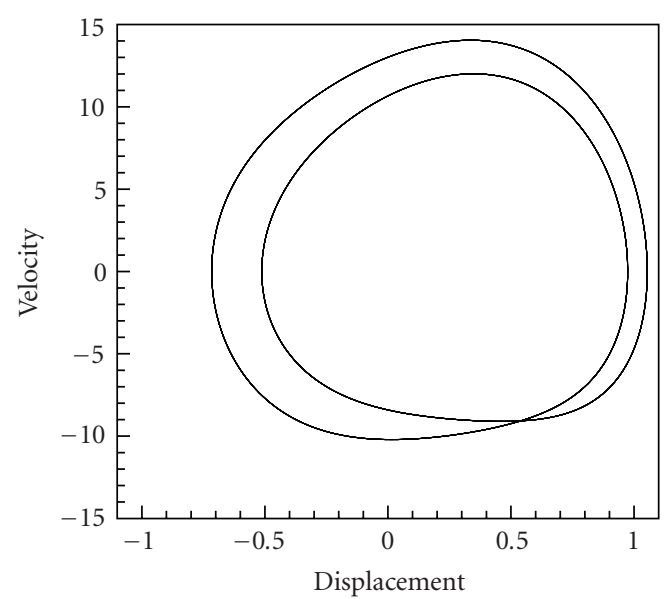

(b)

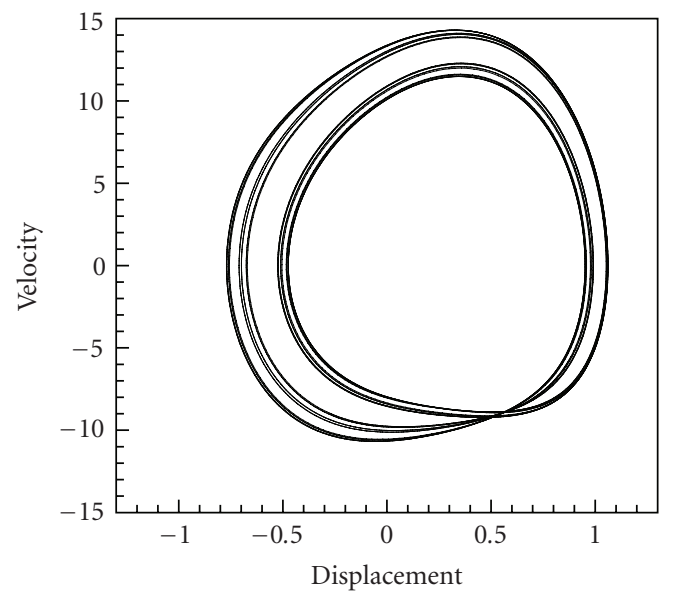

(d)

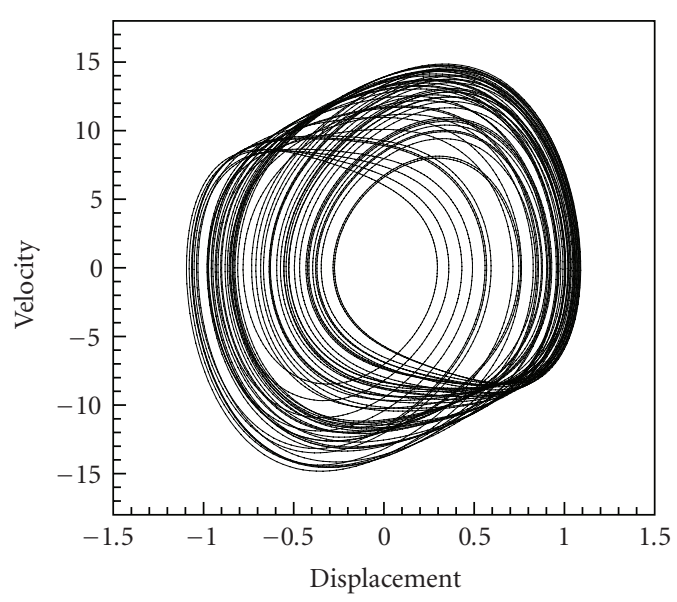

(f)

FIGURE 2: Theoretical phase portraits of the free-end of the pipe, with motion constraints modeled by a cubic spring and 2 d.o.f., for different flow velocities.

Before closing this section, it ought to be noted that the fluid velocity flowing in curved pipes was assumed to be steady, in all the related work cited in the foregoing. More significantly, the geometric nonlinearities induced by the deformation of curved pipes have been neglected in [46-48]. If, however, the fluid velocity is not steady and the geometric nonlinearities are considered, the nonlinear dynamics of the curved pipe may be much richer. 


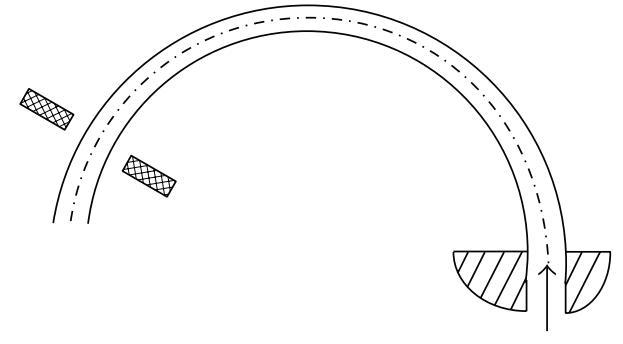

Flow in

FIGURE 3: Schematic of a fluid-conveying curved pipe with motion constraints.

\section{Vibrations of Nanotubes Conveying Fluid}

After the invention of carbon nanotubes (CNTs) by Iijima [54], it has been shown that CNTs have good electrical and mechanical properties and so they have potential applications in design for nanoelectronics, nanodevices, nanocomposites, and so forth, [55]. Because of perfect hollow cylindrical geometry and high mechanical strength, CNTs hold substantial promise as nanocontainers for gas storage, and as nanopipes for conveying fluid (such as gas or water) [56-58]. It is not surprising, therefore, fluid flowing inside CNTs has become an attractive research topic [59-62].

In an attempt to understand and be able to predict the fluid-structure interactions in CNTs conveying fluid, Tuzun et al. [63] developed molecular dynamics simulations of fluids flowing through CNTs. It was found that in a fluid conveying CNT system, the motion of the CNTs plays a significant role in the fluid flow. For example, a fluid flowing through the CNTs tends to straighten out the CNT as it flexes, and simultaneously excites longitudinal vibration modes of the CNTs.

Since molecular dynamic simulations are difficult for large-scale systems, continuum mechanics models have been utilized to investigate the vibrational behavior of CNTs conveying fluid [64-70]. Natsuki et al. [64] studied the wave propagation in single- or double-walled carbon nanotubes (DWCNTs) filled with internal flowing fluids by using an elastic shell model.

On the other hand, the transverse vibrations of fluidconveying CNTs by using Euler beam theory, have been studied recently. Yoon et al. $[65,66]$ have developed a singleelastic Euler beam model for vibrating CNTs containing flowing fluids, both for the cantilevered and supported systems. It was found that the effect of fluid flow velocity on the resonant frequencies of CNTs is significant. Structural instability of the CNTs could occur at a critical flow velocity. The critical flow velocity could cover the range of practical interest. However, the effects of flow velocity on the resonant frequencies and the instability of CNTs would be mitigated when a CNT is embedded in a surrounding elastic medium (such as polymer matrix). As pointed out by Yoon et al. [65], the available data in the literature showed that the flow velocity inside CNTs might range from $400 \mathrm{~m} / \mathrm{s}$ to $2000 \mathrm{~m} / \mathrm{s}$, or even up to $50000 \mathrm{~m} / \mathrm{s}$, in spite of the fact that the available data for flow velocity of water inside CNTs (of very small innermost diameter) are much lower than this value. In 2007, Reddy et al. [67] investigated the effect of fluid flow on the free vibration and instability of fluid-conveying single-walled carbon nanotubes (SWCNTs), using both atomistic and Euler beam models. Wang et al. [68] reported some results of an investigation into the influence of internal flowing fluid on the coupling vibration of fluid-filled CNTs; again, the Euler beam model was used. Recently, Wang and $\mathrm{Ni}$ [69] further analyzed the fluid-conveying CNT model developed by Yoon et al. [65] and explored the possible postdivergence flutter existing in the same dynamical model. Of course, the postdivergence flutter was predicted by the linear theory. More recently, Wang et al. [70] considered the thermal effect on the vibration and instability of a fluid-conveying CNT. Based on the Euler beam theory, it was concluded that at low or room temperature the critical fluid velocity for nanotube including the thermal effect is larger than that excluding the thermal effect and increases with the increase of temperature change. At high temperature the critical fluid velocity for the nanotube including the thermal effect is smaller than that without considering the thermal effect and decreases with the increase of temperature change.

It is noted that [65-70] only considered the vibrations of single-walled carbon nanotubes conveying fluid. Continuing this line of investigation, the flow-induced vibrations of DWCNTs (Figure 5) or MWCNTs conveying fluid were also examined by using Euler beam theory [71-74]. Based on the multiple-elastic beam model, the van der Waals interaction between tubes has been accounted for, showing some important results.

Finally, it ought to be stressed that, in [65-74], the vibration and stability of nanotubes conveying fluid were described by the Euler beam model, which also has been utilized to predict the dynamics of straight pipe conveying fluid, as discussed in Section 2. Therefore, the effect resulting from the small (nano-) scale on the vibrational properties of nanotubes conveying fluid has not been included so far. Although the Euler beam model and several other classical continuum models are relevant to some extent, the length scales associated with nanotechnology are often sufficiently small to call the applicability of continuum models into question. The main reason is that at small length scales the material microstructure (such as lattice spacing between individual atoms) becomes increasingly important. The effects of these small length scales can no longer be ignored. This has raised a major challenge to the classical continuum mechanics. Therefore, a possible solution is to develop some new fundamental theories based on the classical continuum models. Such new theories would account for the small length scales by incorporating information regarding the behavior of material microstructure.

\section{Dynamics of Tubular Beams Subjected to Both Internal and External Axial Flows}

Because of important applications and academic requirements, the vibration and stability of a tubular beam system, subjected to both internal and external axial flows, have 


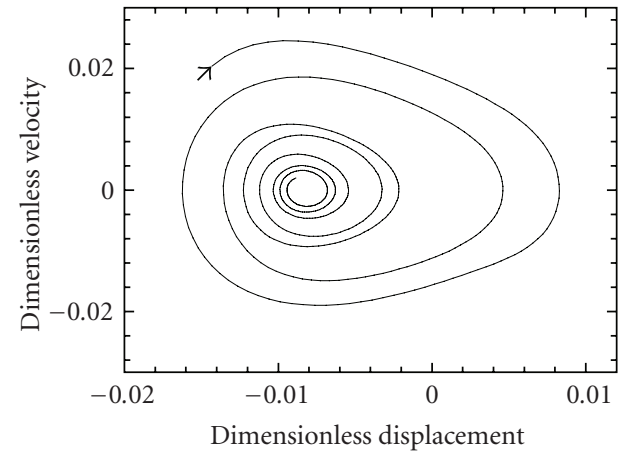

(a)

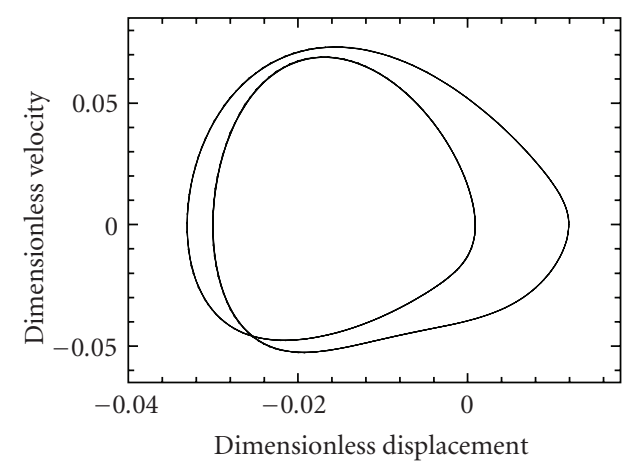

(c)

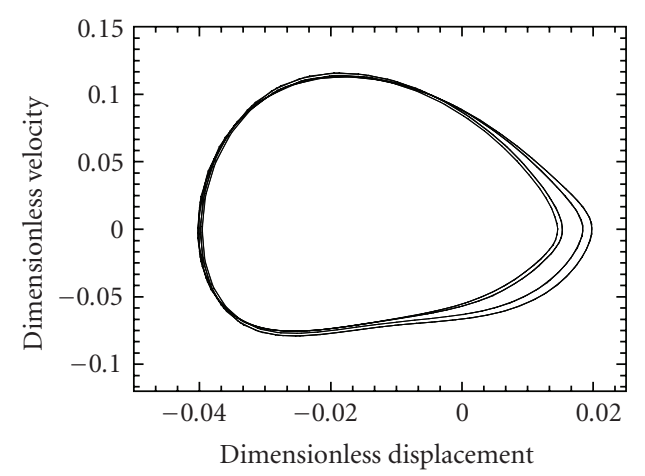

(e)

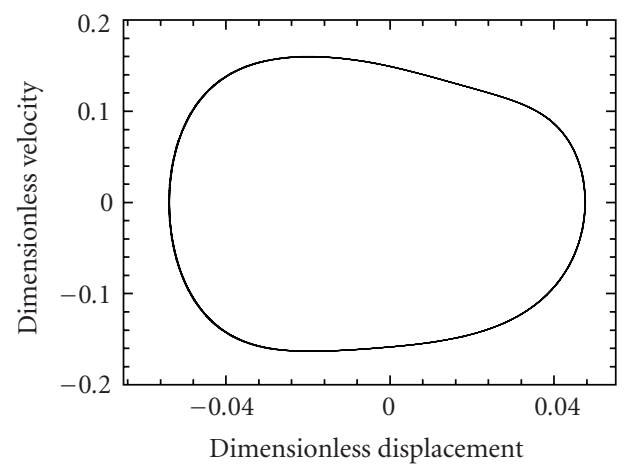

(g)

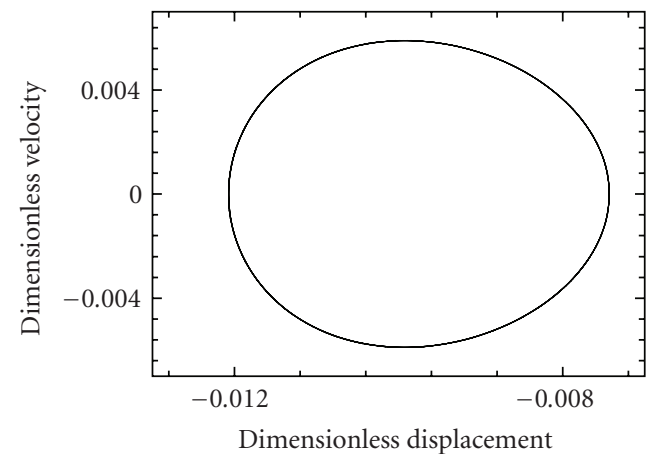

(b)

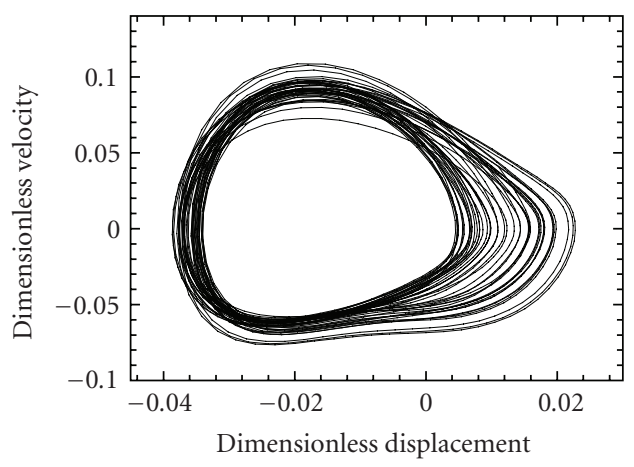

(d)

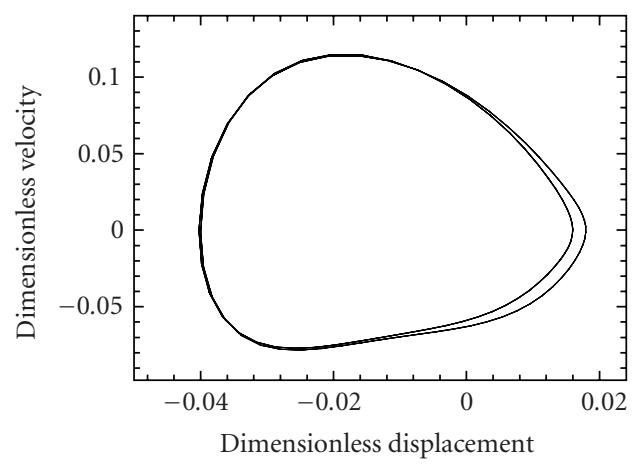

(f)

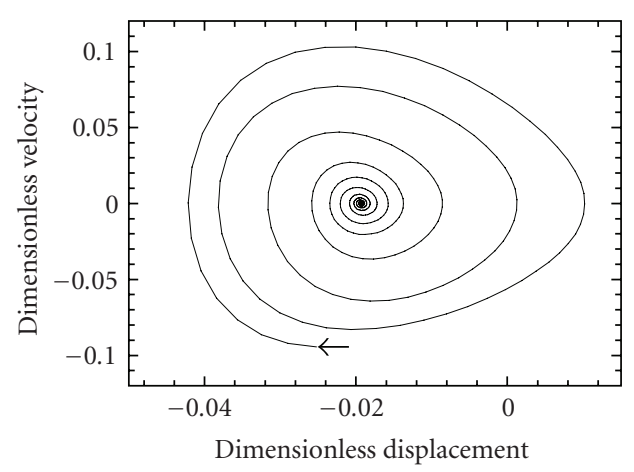

(h)

FIGURE 4: Theoretical phase portraits of the free-end of the curved pipe, with motion constraints modeled by a cubic spring, for different flow velocities; from [47]. 


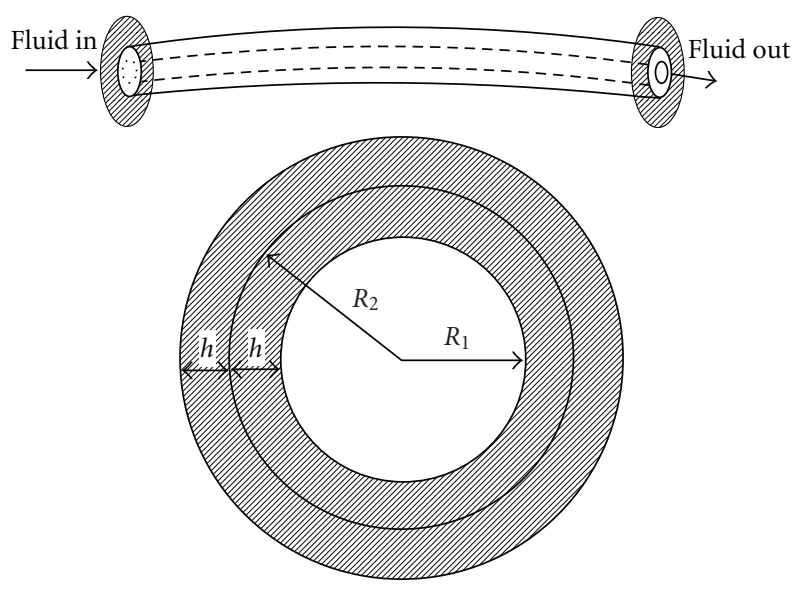

FIGURE 5: Schematic of a DWCNTs with internal fluid flow.

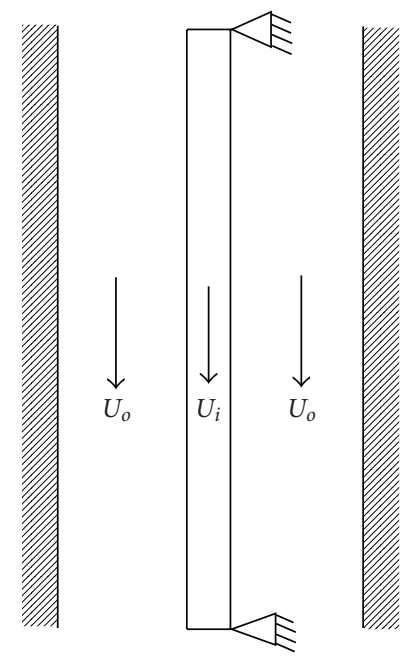

(a)

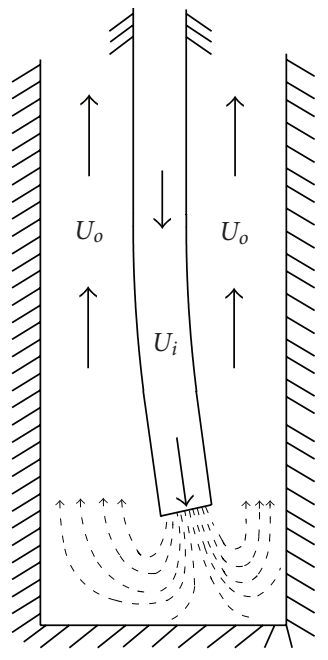

(b)
Figure 6: (a) Schematic of a tubular beam subjected to both internal and external axial flows; (b) the system considered in [83].

been studied by many investigators in the past decades. In Figures 6(a) and 6(b), two typical tubular beam systems are given. The configuration of Figure 6(b) thus resembles that of a drill-string with a floating fluid-powered drill-bit; for example, several related models developed in [3, 75-77].

It is noted that, the tubular beams shown in Figure 6 are subjected concurrently to internal and external axial flows. In fact, the problem of a tubular beam subjected to both internal and external flows has been studied before, by many investigators. Cesari and Curioni [78] have studied the buckling instability in tubular beams subject to internal and external axial flows. Hannoyer and Païdoussis [79] combined theory and experiments on the linear vibrations and stability of a tubular beam with two supported ends or cantilevered, subject to both internal and external axial flows; they found multiple divergence and flutter instabilities. Theory and experiments were in quite good agreement. At about the same time, Grigoriew [80] considered a drill beam with an initial curvature in the axial stream and analyzed its stability. Another notable work by Païdoussis and Besancon [81] discussed various aspects of the vibrations and stability of clusters of tubular beams conveying internal fluid and surrounded by a confined external axial flow. By calculating the eigenfrequencies of the tubular beam system and studying their evolution with various flow velocities of either internal or external fluid, the free vibrations were investigated. Wang and Bloom [82] formulated a mathematical model to study the dynamics of a submerged and inclined concentric tubular beam system with internal and external flows, the resonant frequencies of that system obtained and analyzed.

Recently, Païdoussis et al. [83] reported some interesting results on this problem. The basis of that work is Luu's thesis [84]. Luu [84] and Païdoussis et al. [83] differed from the work of [78-82] in two significant ways: first, the external and axial flows are countercurrent, and second the two flows are not independent of each other (see Figure 6(b)). In the study by Païdoussis et al. [83], a theoretical model was developed for the dynamics of a hanging tubular cantilever, centrally located in a cylindrical container, with fluid flowing downwards inside the cantilever. The internal fluid, after exiting from the free-end, is deflected at the bottom of the container, and thereafter flows upwards in the annular space between the cantilever and container. It is noted that the configuration developed in Païdoussis et al. [83] was inspired by the geometry of a drill-string with a drill-bit at the lower end.

The drill-string-like system considered in [83] consists of a uniform tubular beam of length $L$, external cross-sectional area $A_{o}$, flexural rigidity $E I$, and mass per unit length $M_{t}$, conveying downwards incompressible internal fluid of mass per unit length $M_{f}$, flowing axially with constant velocity $U_{i}$. The internal fluid leaving the lower end of the tubular beam then flows upwards with velocity $U_{o}$ within an outer rigid channel. The linear equation of motion for this system can be written as [83]

$$
\begin{aligned}
& E I \frac{\partial^{4} w}{\partial x^{4}}+M_{t} \frac{\partial^{2} w}{\partial t^{2}}+M_{f}\left(\frac{\partial^{2} w}{\partial t^{2}}+2 U_{i} \frac{\partial^{2} w}{\partial x \partial t}+U_{i}^{2} \frac{\partial^{2} w}{\partial x^{2}}\right) \\
& +\chi \rho_{f} A_{o}\left(\frac{\partial^{2} w}{\partial t^{2}}-2 U_{o} \frac{\partial^{2} w}{\partial x \partial t}+U_{o}^{2} \frac{\partial^{2} w}{\partial x^{2}}\right) \\
& -\left[\left(T-A_{f} p_{i}+A_{o} p_{o}\right)_{L}+\left(M_{t}+M_{f}-\rho_{f} A_{o}\right) g(L-x)\right. \\
& \left.\quad-\frac{1}{2} C_{f} \rho_{f} D_{o} U_{o}^{2}\left(1+\frac{D_{o}}{D_{h}}\right)(L-x)\right] \frac{\partial^{2} w}{\partial x^{2}} \\
& +\left[\left(M_{t}+M_{f}-\rho_{f} \mathrm{~A}_{o}\right) g-\frac{1}{2} C_{f} \rho_{f} D_{o} U_{o}^{2}\left(1+\frac{D_{o}}{D_{h}}\right)\right] \frac{\partial w}{\partial x} \\
& +\frac{1}{2} C_{f} \rho_{f} D_{o} U_{o} \frac{\partial w}{\partial t}+k \frac{\partial w}{\partial t}=0,
\end{aligned}
$$

where $w(x, t)$ is the lateral deflection of the tubular beam and $t$ is time; $\rho_{f}$ is the mass density of the fluid; $g$ is the acceleration due to gravity; $C_{f}$ and $k$ are the viscous damping coefficients; $T_{L}$ is the axial tension, induced by the fluid 


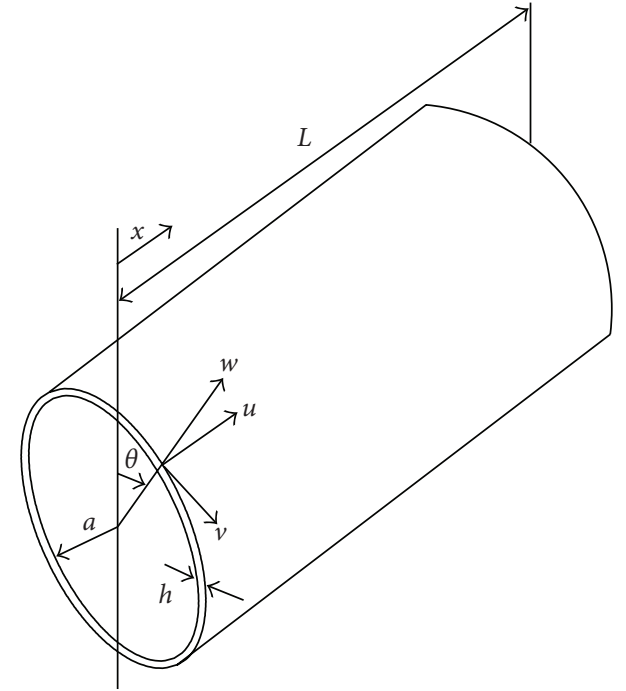

FIgURE 7: A cylindrical shell, showing some key dimensions.

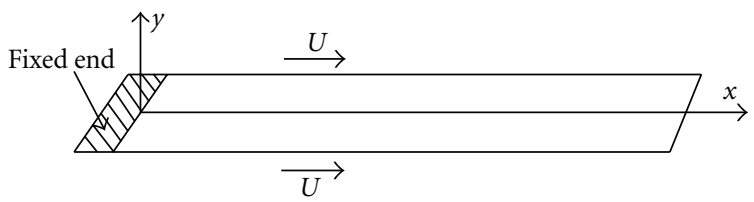

FIGURE 8: Schematic of a solitary plate in axial flow.

pressure at the lower end; $D_{o}$ is the outer diameter of the tubular beam and $D_{h}$ is the hydraulic diameter of the annular channel flow. The definitions of $p_{o L}, p_{i L}$ and $\chi$ can be found in $[83]$.

Based on numerical calculations, Païdoussis et al. [83] have analyzed the evolution of the eigenfrequencies. It was found that, if the annular space is wide, the dynamics is dominated by the inside flow (i.e., the flow within the drill-string), for low-flow velocities, the flow increases the damping associated with the presence of the annular fluid; if the annular space is narrow, however, the annular flow is dominant, tending to destabilize the system, giving rise to flutter at remarkably low-flow velocities.

From the viewpoint of string-drill dynamics these results are interesting for the following reason: it was shown that, even if the drill-bit never makes mechanical contact with the drill-string, the system experiences flutter type of instability; and hence the string would soon touch the surrounding walls. In a real system, however, effective contact between the drill-bit and the drill-string is inevitable, and so the dynamics is more likely to resemble those of a pipe with clamped or pinned ends [83].

\section{Dynamics of Cylindrical Shells Subjected to Axial Flow}

Of academic and practical interest is the dynamics of thinwall pipes conveying fluid. For very thin pipes conveying fluid, Païdoussis and Denise $[85,86]$ accidentally found that this type of pipe systems are not only subject to beamtype, but also to shell-type instabilities. For sufficiently highflow velocities, if the thin pipe is relatively short, then the instability observed is not one of lateral motions of the pipe ( $n=1$, where $n$ is the circumferential mode number), but rather involves deformation of the pipe cross-section; that is, the instability is associated with a shell-type breathing mode (typically $n=2$ or 3 ). When the diameter of the middle surface of the thin-wall pipe is relatively large, the problem should be analyzed by using elastic shell theory. In the past decades, the subject was studied theoretically and experimentally, both for clamped-clamped and cantilevered shells.

Consider a cylindrical shell either conveying fluid or immersed in an axial flow, as shown in Figure 7. In this case, however, the internal flow can no longer be treated as a plug flow, but rather as a three-dimensional one. The linear equations of motion may be written as [86]

$$
\begin{gathered}
\ell_{1}(u, v, w)=\gamma \frac{\partial^{2} \mathrm{u}}{\partial \mathrm{t}^{2}}, \quad \ell_{1}(u, v, w)=\gamma \frac{\partial^{2} v}{\partial t^{2}}, \\
\ell_{1}(u, v, w)=-\gamma\left[\frac{\partial^{2} w}{\partial t^{2}}-\frac{q_{\mathrm{r}}}{\rho_{\mathrm{s}} h}\right],
\end{gathered}
$$

in which $\ell_{\mathrm{i}}(i=1,2,3)$ denote linear differential operators of the axial coordinate $x$ and the circumferential angle $\theta ; u, v$ and $w$ are defined, respectively, as the axial, circumferential and radial displacements of the middle surface of the shell; $q_{r}$ is the radial surface loading per unit area, which can be written as

$$
q_{r}=p_{i}-p_{e}
$$

In the above equation, $p_{i}$ and $p_{e}$ are the internal and external pressures exerted on the shell. The fluid is assumed to be inviscid and incompressible for simplicity; the flow is irrotational. Moreover, $p_{i}$ and $p_{e}$ are supposed to be composed of mean steady components and the perturbation components.

If the effect of the steady components is ignored, the perturbation components may be obtained via potential flow theory [86] and can be written as

$$
\begin{aligned}
& p_{i}^{*}=-\frac{\rho_{i} a}{n+\lambda I_{n+1}(\lambda) / I_{n}(\lambda)}\left[\frac{\partial}{\partial t}+U_{i} \frac{\partial}{\partial x}\right]^{2} w \\
& p_{e}{ }^{*}=-\frac{\rho_{e} a}{n-\lambda K_{n+1}(\lambda) / K_{n}(\lambda)}\left[\frac{\partial}{\partial t}+U_{e} \frac{\partial}{\partial x}\right]^{2} w,
\end{aligned}
$$

at $r=a-0^{+}$and $r=a+0^{+}$, respectively, for $h / a \ll 1(h$ and $a$ are defined in Figure 7$)$. In the above two equations, $\rho_{\mathrm{i}}$ and $\rho_{\mathrm{e}}$ are the fluid densities of the internal and external flows, respectively; $U_{i}$ and $U_{e}$ are, respectively, defined as the internal and external flow velocities; $\lambda$ and $n$ are the axial wavenumber and the circumferential wavenumber, respectively. For the particular case of the internal or external fluid being quiescent, (9) and (10) still apply but with $U_{i}=0$ or $U_{o}=0$. 
It can be seen that the terms arising from the squarebrackets operator in (9) and (10) can be written as $\partial^{2} w / \partial t^{2}+$ $U^{2} \partial^{2} w / \partial x^{2}+2 U \partial^{2} w / \partial x \partial t$. These various terms are associated, respectively, with the inertia of the fluid, and the centrifugal and Coriolis forces of the moving fluid. Thus, the fluid effect is wholly analogous to that acting on a straight pipe conveying fluid. It is not surprising that the mechanism of underlying instabilities appears to be quite similar to that of beam-like instabilities of pipes conveying fluid. If the shell is supported at both ends, corresponding to a conservative system, it loses stability by divergence at a certain flow velocity. For a slightly higher flow velocity, the shell may subject to a coupled-mode flutter. Once again, the reliability of the postdivergence flutter predicted by means of linear theory is questionable and hence needs to be re-examined by means of nonlinear theory, as discussed later.

In the case of a cantilevered shell conveying internal fluid, corresponding to a nonconservative system, the instability is in the form of single-mode flutter, similar to the case of thicker pipes. The dynamics with external flow is quite similar to that with internal flow. This form of single-mode flutter is what was observed experimentally $[85,86]$.

Experiments with elastomer shells and air-flow showed that cantilevered shells lose stability by flutter, as predicted by theory $[86,87]$. In the case of shells with clamped ends, however, the dynamics observed in experiments with internal and external flows were quite different: with external flow the system lost stability by divergence, while with internal flow the system lost stability by flutter $[86,88]$. Therefore, the dynamics of shells conveying internal fluid predicted by linear theory did not agree with that observed experimentally, since divergence has not been detected in experiments. It would seem that re-examination of the dynamics was necessary. Clearly, this re-examination must involve both nonlinear theory and further experiments. This was discussed in greater detail by Karagiozis et al. [89-91] and Païdoussis [13].

The question of nonoccurrence of divergence in experiments with shells conveying internal flow was resolved $[13,92]$ by conducting experiments with stiffer shells. It was found that the stiffer shells did indeed lose stability by divergence, which is what is predicted by theory.

Based on the nonlinear theory, Amabili et al. [93] further analyzed a shell with simply supported ends conveying fluid. They predicted that the shell would lose stability by divergence via a strongly subcritical pitchfork bifurcation. However, they did not develop coupled-model flutter. As the experiments [89] were always done with shells with clamped ends (for experimental convenience), a new nonlinear theoretical model was developed for shells with clamped ends $[90,91]$. Again, the postdivergence flutter was not detected. Theory and experiments are in reasonable agreement with each other quantitatively.

\section{Dynamics of Plates in Axial Flow}

Vibration of flexible plates due to axial flow is an important issue, for instance, in paper manufacturing and paper printing $[94,95]$, also in parallel-plate assemblies used as core elements in some research and power nuclear reactors.

7.1. Solitary Plate in Axial Flow. First, consider a two dimensional plate of flexural rigidity $\wp=E h^{3} /[12(1-$ $\left.v^{2}\right)$ ], $E$ and $v$ being the elastic modulus and Poisson ratio, respectively, $h$ being the plate thickness and $\rho_{p}$ the density. The plate is subjected to a flow-related perturbation pressure $p^{*}$. The schematic of the analytical system is shown in Figure 8 . The linear equation of motion can be written as

$$
\wp \frac{\partial^{4} w}{\partial x^{4}}+C_{d} \frac{\partial w}{\partial t}+\rho_{P} h \frac{\partial^{2} w}{\partial t^{2}}=-p^{*},
$$

where $C_{d}$ is viscous damping coefficient. It is assumed that the flow is inviscid, the complete solution for $p^{*}$ has been obtained by Kornecki et al. [96] and is given by

$$
\begin{aligned}
& -p^{*}=\frac{\rho}{\pi L}\left\{\int_{0}^{1}\left[L^{2} \frac{\partial^{2} w}{\partial t^{2}}+2 U L \frac{\partial^{2} w}{\partial \xi \partial t}+U^{2} \frac{\partial^{2} w}{\partial \xi^{2}}\right]\right. \\
& \times \ln |\bar{x}-\xi| \mathrm{d} \xi-R(\bar{x})\},
\end{aligned}
$$

where

$$
\begin{aligned}
& R(\bar{x})=U^{2}\{ {\left[w^{\prime}(1)+(L / U) \dot{w}(1)\right] \ln (1-\bar{x}) } \\
&\left.-\left[w^{\prime}(0)+(L / U) \dot{w}(0)\right] \ln \bar{x}\right\},
\end{aligned}
$$

in which $\bar{x}$ and $\xi$ are defined by $\bar{x}=x / L$ and $\xi=u / L$, respectively, $u$ being a dummy variable; $t$ is dimensional time; $\rho$ is the fluid density.

The terms given in the square-brackets on the righthand side of (12) have the similar functional form as in (1), and the function $\ln |\bar{x}-\xi|$ may be viewed as the effect of spatial memory. The difference in the theories mentioned in Sections 2, 3, 4, 5, and 6 and that for the plate here is significant. For pipes, tubular beams and shells of the local fluid forces depend only on the local displacement. For the plate problem, however, the local fluid forces depend on the global flow field.

By using linear theory, it has been found that a plate with supported ends loses stability by divergence and then by coupled-model flutter subsequently. These theoretical findings were broadly supported by experiments conducted by Dugundji et al. [97]. It is recalled that, for fluid-conveying pipes with both ends supported, the coupled-model flutter instability, which is predicted by the linear theory, has not been observed experimentally. In the case of supported plates subjected to axial flow, however, this coupled-model flutter was indeed observed in experiments.

For a cantilevered plate subjected to axial flow, the dynamics is much clearer; the system loses stability by flutter, as predicted by theory. Also, this form of instability has been observed experimentally. The similarity in the form of the fluttering plate to a fluttering pipe, in all its features, is quite remarkable. In the case of a cantilevered plate, however, the prediction is much more complicated, since the vorticity shed by the flapping plate into the wake should be taken into account [97-100]. 
More recently, Tang and Païdoussis [101-103] further investigated the instability and nonlinear vibrations of twodimensional cantilevered plates in axial flow. In [101, 102], a nonlinear equation of motion has been utilized, assuming the middle plane of the plate to be inextensible, together with the unsteady lumped-vortex model for calculating the unsteady fluid loads. The flutter boundary obtained was compared with available experimental data. It was found that, when the plate is long, the theoretical predictions are in very good agreement with measurements from different experiments. In contrast, agreement with experiments is rather poor for short plates. In another recent work reported by Tang and Païdoussis [103], the nonlinear vibration of the same dynamical system developed in $[101,102]$ was further studied. However, an additional spring support of either linear or cubic type was installed at various locations on the plate. When the flow velocity is sufficiently high, the plate was predicted to exhibit chaotic motions via a period-doubling route. However, these interesting dynamical behaviours should be examined experimentally.

7.2. Parallel-Plate Assembly. A parallel-plate assembly, generally, consists of many thin plates stacked in parallel; between these parallel plates there are narrow channels to let coolant flow through. The main problem in this type of fuel system is the static and/or dynamic instabilities due to the flowing fluid. In some practical tests, large deflections and/or flutter were observed when the flow velocity became sufficiently high (see, e.g., [104-107]). The large deflections and/or flutter might lead to failure in practice.

Many attempts have been made to theoretically analyze the vibrations and study instability. Perhaps the first study on this problem was by Miller [108], who presented a theory for predicting the critical velocity for static divergence (collapse) of parallel-plate assembly. In his analysis, based on widebeam theory and Bernoulli's theorem, the critical velocity was obtained by equating pressure differences between channels to the elastic restoring force of a plate. Miller's theory was further improved by Johansson [109], who included the effects of fluid friction and flow redistribution. Scavuzzo [110] and Wambsganss [111] made further improvements upon Miller's and Johansson's model by considering the nonlinearity caused by large deflections (i.e., geometric nonlinearity). Rosenberg and Youngdahl [112] formulated a dynamical model and obtained the same critical velocity by using a two-dimensional mode. Yang and Zhang [113] developed a multispan elastic beam model to imitate a typical substructure of a parallel-plate structure. In their analytical model, there exists a narrow channel between the lower surface of the wide beam and the upper surface of the bottom plate of the water trough. By using the added water mass and damping coefficients, the free vibrational frequencies of the system were analyzed. Yang and Zhang [114] further investigated a parallel flat plate-type structure in rigid water trough or rigid rectangular tube.

More recently, Guo and Païdoussis [115] developed a more accurate and general theoretical analysis for parallelplate assembly system. In their analysis, the plates were treated as two dimensional, with a finite length, and the flow field is taken to be inviscid, three dimensional. In [115], the equation of motion of an elastic plate is given by

$$
\wp\left(\frac{\partial^{4} w}{\partial x^{4}}+\frac{\partial^{4} w}{\partial x^{2} \partial y^{2}}+\frac{\partial^{4} w}{\partial y^{4}}\right)+\rho_{P} h \frac{\partial^{2} w}{\partial t^{2}}+P^{*}=0
$$

where $P^{*}=P^{*}(x, y, t)$ may be viewed as the net load per unit area on the plate, equal to the difference between the perturbation pressures on the upper and lower surfaces of the plate caused by its deflection. Because of antisymmetry with respect to the plate, the perturbation pressures on the upper and lower surfaces must be equal in magnitude, but opposite in sign.

Based on (14), several important conclusions were [115] (i) single-mode divergence, mostly in the first mode, and coupled-mode flutter involving adjacent modes were found; (ii) the frequencies at a given flow velocity and the critical velocities increase as the aspect ratio decreases; (iii) in the case of large aspect ratios and small channel-height-toplate-width ratios, the plates lose stability by first-mode divergence, however, very short plates usually lose stability by coupled-model flutter in the first and second modes; (iv) critical velocities for both divergence and flutter are insensitive to changes in damping coefficients.

Before closing this section, it should be remarked that most studies discussed in the foregoing were based on linear theories for parallel-plate assembly. Unfortunately, the literature on the nonlinear dynamics of such type of structures is very limited. If the essential nonlinearity is accounted for, the dynamical behaviour may be much richer.

\section{Dynamics of Slender Structures in Axial Flow or Axially Towed in Quiescent Fluid}

8.1. Slender Structures in Axial Flow. As indicated in the Introduction, although most failures of slender structures (mostly cylinders or rods) are associated with the conditions of cross-flow, the cases of axial flow have also been shown to be of significance. In the first such study, motivated by application to the vibration of fissile fuel rods in nuclear reactors, Païdoussis [116] has investigated the dynamics of cylinders or rods in axial flow. In his two later papers, Païdoussis [117, 118] led to a still-used semi-empirical relation for predicting the turbulence-induced vibration levels in such systems.

Further research, however, was mainly driven by curiosity. Nevertheless, many applications can be found in practice. These applications should include, but not limited to (i) dynamics of rods and reactivity monitors in nuclear reactors; (ii) the vibration in closely spaced clusters of cylinders; (iii) the turbulence-induced vibration of tube (or cylinder) arrays in heat exchangers.

8.1.1. Solitary Cylinders or Rods. The schematic of a cantilevered cylinder in axial flow is shown in Figure 9. As developed in [119], the simplest form of the linear equation 


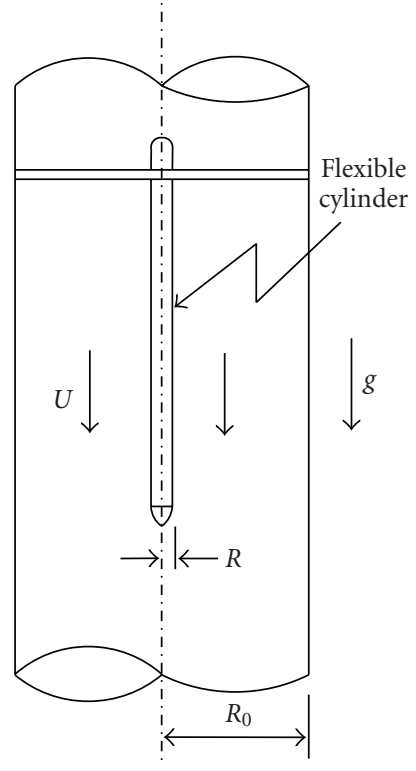

FIGURE 9: Schematic of a hanging cylinder in axial flow.

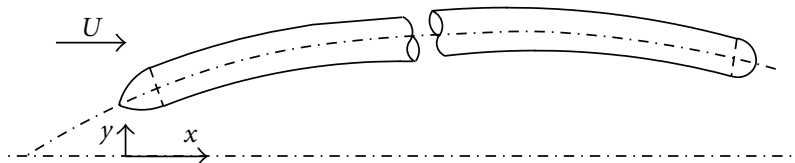

FIGURE 10: Idealized system of a towed cylinder with noncylindrical "nose" and "tail" segments.

of motion of a cylinder in axial flow may be written as

$$
\begin{gathered}
E I \frac{\partial^{4} w}{\partial x^{4}}+M U^{2} \frac{\partial^{2} w}{\partial x^{2}}+2 M U \frac{\partial^{2} w}{\partial x \partial t}+(m+M) \frac{\partial^{2} w}{\partial t^{2}} \\
-\left[\frac{1}{2} \rho D U^{2} C_{T}(L-x)+\frac{1}{2} \rho D^{2} U^{2} C_{b}\right] \frac{\partial^{2} w}{\partial x^{2}} \\
+\frac{1}{2} \rho D U C_{N}\left(\frac{\partial w}{\partial t}+U \frac{\partial w}{\partial x}\right)+\frac{1}{2} \rho D C_{D} \frac{\partial w}{\partial t}=0
\end{gathered}
$$

where $M=\rho A$ is the virtual, or added, mass of the fluid per unit length for unconfined flow, $A$ being the cross-sectional area of the cylinder and $\rho$ the fluid density, $w(x, t)$ is the lateral deflection, $C_{T}$ and $C_{N}$ are viscous force coefficients in the longitudinal and normal direction, respectively, $C_{D}$ is the linearized zero-flow viscous drag coefficient for lateral motions, $C_{b}$ is the base drag coefficient, $D$ is the diameter of the cylinder, and the other symbols are the same as for internal flow.

If both ends are supported, the equation of motion is slightly more complicated, depending also on whether the downstream end is free to slide axially, pressurization of the external fluid, and so on.

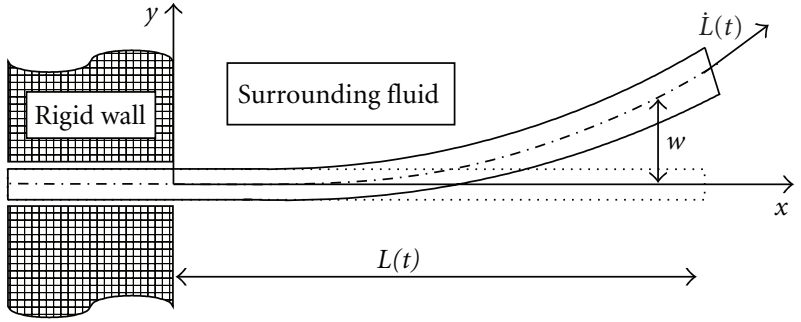

(a)

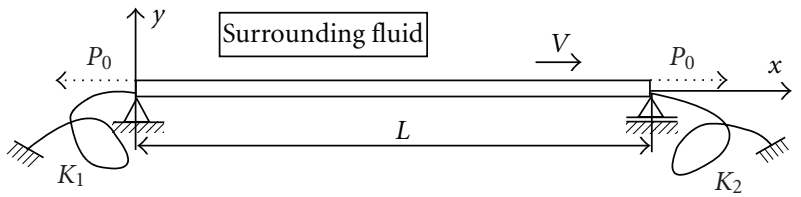

(b)

FIGURE 11: The cantilevered and supported axially moving beams. (a) The system considered in [7]. (b) The system considered in [8].

In the case of a cantilevered cylinder, it was generally supposed that the free-end is ogive-shaped. The simplest of the boundary conditions are

$$
\begin{gathered}
E I \frac{\partial^{2} w}{\partial x^{2}}=0 \\
E I \frac{\partial^{3} w}{\partial x^{3}}+f M U\left(\frac{\partial w}{\partial t}+U \frac{\partial w}{\partial x}\right)-(m+f M) x_{e} \frac{\partial^{2} w}{\partial t^{2}}=0
\end{gathered}
$$

where $x_{e}=(1 / A) \int_{L-1}^{L} A(x) \mathrm{d} x, l$ being the length of the shaped end; $f$ is a parameter first introduced by Hawthorne [120], equal to unity for a truly streamlined end. However, $f$ is generally smaller because of 3D flow over the free-end and boundary-layer effects.

From (15), it is immediately seen that its first line is identical to the equation of motion of straight pipes conveying fluid (see (1)). Examining (15), it can be found that its second line is associated with the viscosity of the fluid. In fact, (1) and (15) differ only because of the viscous terms constituting in (15). Generally, the viscous terms are small compared to the first four terms in (15). Therefore, it may be expected that the dynamics, for cylinders with supported ends at least, is similar to that of the fluid-conveying pipe. This similarity is confirmed by Païdoussis [119].

For a cylinder with simply supported ends, as discussed in [119], divergence can be predicted at a nondimensional flow velocity only slightly higher than $\bar{U}=\pi$ in the first mode, followed at $\bar{U} \approx 2 \pi$ by divergence in the second mode. Coupled-flutter is predicted at $\bar{U} \approx 6.48$. Indeed, postdivergence (couple-mode) flutter has been observed in experiments [121]. In fact, recent calculations by means of nonlinear theory have confirmed the existence of postdivergence flutter [122], and more recently reconfirmed experimentally [123]. In the study of [122], it was found that a Hopf bifurcation arises from loss of stability of the trivial equilibrium state. More interestingly, the system displays 


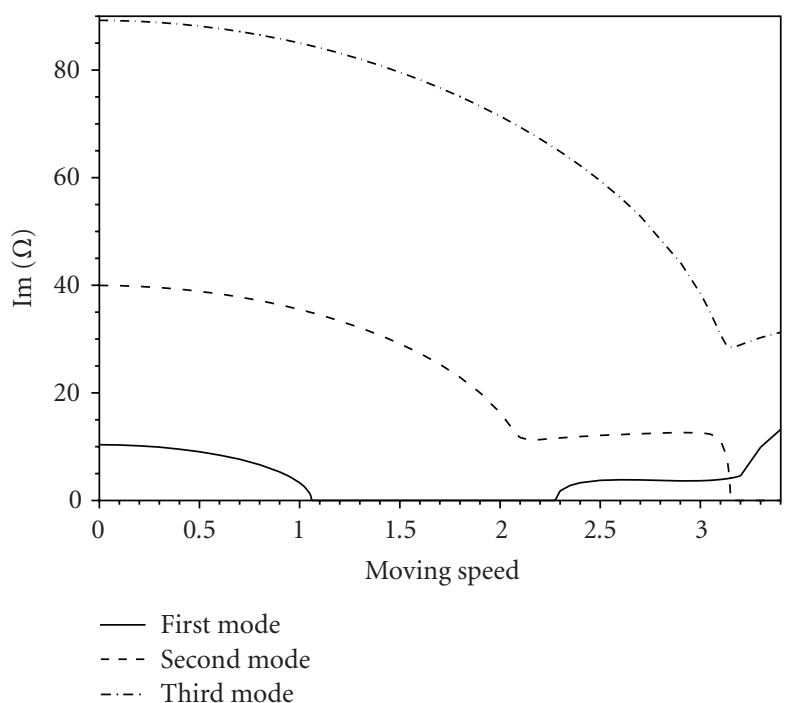

(a)

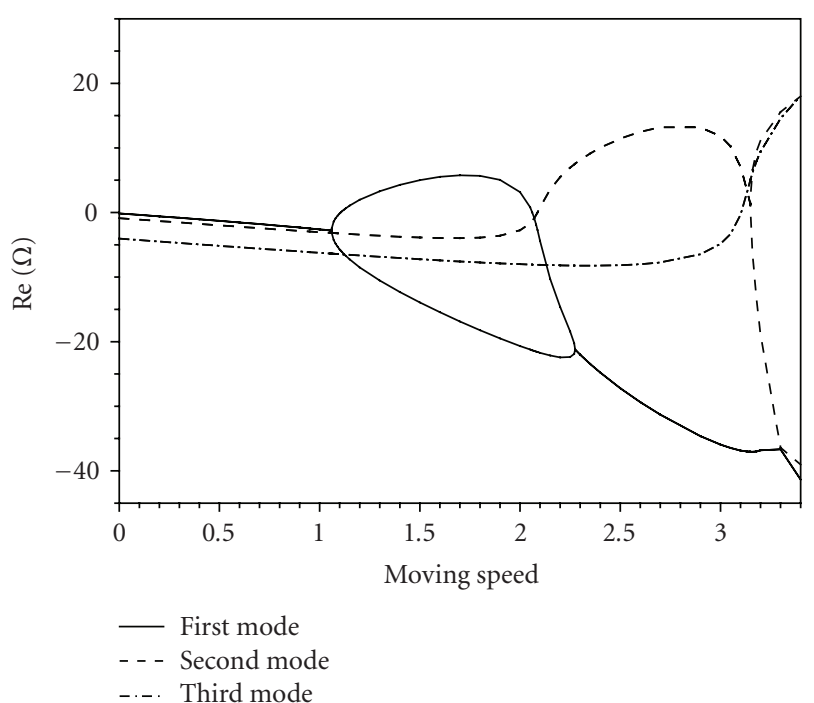

(b)

FIGURE 12: The imaginary and real components of the dimensionless frequency, $\Omega$, as functions of the moving speed, $\bar{V}$, for the lowest three modes of a pinned-pinned beam; from [8].

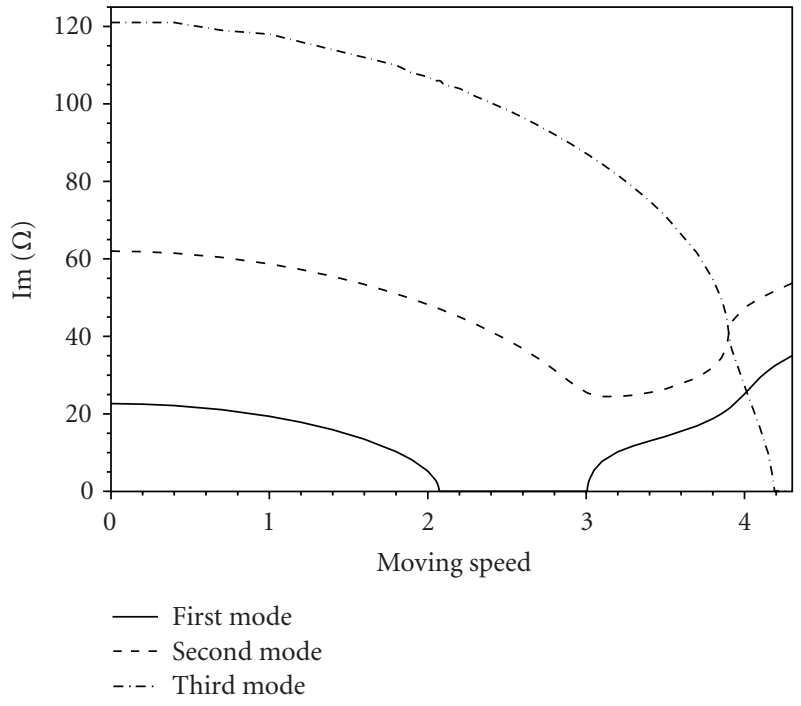

(a)

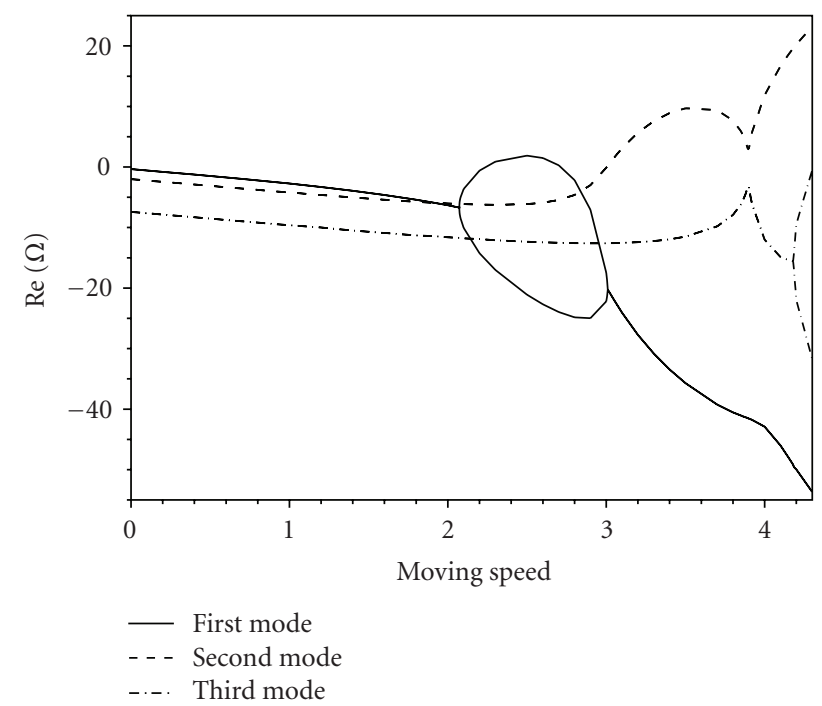

(b)

FIGURE 13: The imaginary and real components of the dimensionless frequency, $\Omega$, as functions of the moving speed, $\bar{V}$, for the lowest three modes of a clamped-clamped beam; from [8].

quasiperiodic and chaotic motions at higher flows, of course, predicted by means of nonlinear theory.

The dynamics of a cantilevered system should be discussed here, since it is not similar to that of a cantilevered pipe conveying fluid. As reported in [119], for $f=0.8$, the cantilevered system first loses stability by divergence at $\bar{U} \approx 2.04$, and then by single-mode flutter at $\bar{U} \approx 5.16$, and after restabilization by flutter in the third mode at $\bar{U} \approx 8.17$. The reader may be surprised by the fact that the cantilevered system first loses stability by divergence at low-flow velocity. The reason is that the divergence is related to the presence of the tapered free-end. It is recalled that the case $f=0.8$ suggests a fairly well-streamlined end. If $f=0$, however, the end is blunt, and hence divergence is not possible.

The dynamics of cantilevered system predicted by linear theory has been re-examined theoretically, by means of nonlinear theory, and experimentally [124, 125]. It was found that the essential dynamical behaviour is as predicted by linear theory. However, the bifurcations do not arise in the same way.

8.1.2. Clustered Cylinders. The dynamics of clustered cylinders in axial flow has received considerable attention [126, 
127], because such systems exist in many engineering applications, as discussed in the foregoing.

The vibrations of such cylinders compared with that of isolated cylinder are characterized by (i) the effect of proximity of the other cylinders being important, causing various instabilities to occur at lower flow velocities, and (ii) the effect of intercylinder motion coupling, decreasing the critical flow velocities. Therefore, predicting the critical flow velocities for instability requires one very important piece of data: the cluster geometry and the intercylinder separation. For more details on this topic, one can refer to [127].

8.2. Slender Structures Towed in Quiescent Fluid. A considerable amount of notable work has been conducted on towed cylinders, rods, or tubular beams. Many applications of this system have emerged as follows: (i) vibrations of extruding metal and plastic rods in fluid [6, 7]; (ii) stability and vibrations of extremely long "seismic arrays," mostly towed behind boats and used in mineral exploration in the deep seas; (iii) the vibrations of towed pipelines for easy relocation mostly used in ocean; (iv) the vibrations of articulated submarine transporters; (v) high-speed trains traveling in narrow tunnels.

A sketch of towed slender structures shown in Figure 10 has received considerable attention $[128,129]$. For this dynamical model, it was found that the dynamics with low towing speed is dominated by rigid-body instabilities. At higher towing speeds flexural instabilities might arise, much as for a cantilevered cylinder. Recently, in a work by Langre et al. [130], flutter was indeed found to exist.

Another typical system of a flexible cylinder or a tubular beam axially towed in fluid is shown in Figure 11. In Figure 11(a), a slender cantilevered beam is extending axially in the horizontal direction at a known rate, while immersed in a dense incompressible fluid. This tubular beam system has been studied by Taleb and Misra [6] and Gosselin et al. [7]. In the study by Gosselin et al., the fluid-dynamic forces obtained by Taleb and Misra were perceived to be not correctly accounted for. Thus, Gosselin et al. [7] re-examined the fluid-dynamic forces. It was found that, in the case of low constant extension rates, the system displays a phase of oscillation with increasing amplitude and decreasing frequency until the motion is strongly damped and later becomes statically unstable. For faster deployment rates, the beam has a short flutter phase at the beginning of the deployment, followed by a brief phase of damped oscillation until it exhibits static divergence. For fast enough deployment rates, the system is unstable from the beginning and never stabilizes. It should be mentioned that the effective length of the towed beam is increased with time, since the axially moving beam is clamped-free. It was also found that the axial added mass coefficient plays significant role in the stability of the system.

More recently, an axially towed system in fluid, shown in Figure 11(b), was investigated by Lin and Qiao [8]. Compared with the system in Gosselin et al. [7], this beam system has hybrid supports at both ends. It is worth noting that the formula of the total axial tension $(T(x))$ in the supported beam is different from that in the cantilevered system. In the study of Gosselin et al. [7], a nonzero value of $T(L)$ arises from drag-induced compression at the freeend. Therefore, the final equation of motion of a supported system does differ from that of a cantilevered system. Compared with the cantilevered system, the effective length of the supported beam system keeps constant with time.

Figure 12 [8] shows the effect of moving speed on the variation of the lowest three eigenvalues $\left(\Omega_{1}, \Omega_{2}\right.$, and $\left.\Omega_{3}\right)$ of the moving beam with pinned-pined supports. It was found that the first mode first becomes unstable by divergence instability when the moving speed becomes equal or larger than the lowest critical moving speed (nondimensional) $\bar{V} \approx$ 1.06. However, flutter instability was predicted to occur at a higher moving speed $(\bar{V}=2.27)$ in the first mode. The critical moving speeds at which divergence may occur in the second and third modes were both higher than $\bar{V}=2.27$.

It is of special interest to see the case of clamped-clamped moving beam. In this case, typical results are shown in Figure 13 [8]. It is obviously seen that divergence in the first mode occurs at $\bar{V}=2.072$ and in the third at $\bar{V}=4.18$. However, the second mode was predicted to be stable in the range $0<\bar{V}<4.3$.

\section{Conclusions}

The knowledge base associated with the basic dynamics of slender structures subjected to axial flow or towed in quiescent fluid has expanded greatly in recent years, as the number of applications continues to grow. Obviously, the literature survey is not exhaustive. For example, in Becker's survey [131] associated with the topic of pipes conveying fluid, 223 references were cited; in a more recent review by Païdoussis and Li [132], again, more than 200 references associated with pipes conveying fluid were cited. This paper, therefore, presents a selective review of the research undertaken on the vibrations of slender structures subjected to axial flow or axially towed in fluid. Undoubtedly many important contributions have been missed. Other aspects, which have been covered in a recent book by Païdoussis [133], also have not been fully discussed here.

One item of particular interest to the readers is that the fundamental understanding and experience gained and the methodology employed in the studies of the dynamical model of fluid-conveying pipes has proved to be very useful in the study of several other dynamical models, particularly shells conveying or immersed in axial flow, nanotubes conveying fluid, tubular beams subjected to both internal and external axial flows, cylinders and plates in axial flow, and tubular beams or cylinders axially towed in fluid. As reported in [132], it can be now understood that the dynamics of thin shells containing or surrounded by annular flows, with applications to aircraft engines and some types of nuclear reactors utilizing thermal shields. Similarly, the understanding of the dynamics of heat exchanger tube arrays and nuclear reactor fuel clusters subjected to external axial flows owes a great deal to the understanding gained in the study of pipes conveying internal flow. Furthermore, the 
dynamics of various cylindrical beam-like components subjected to internal or annular flows (e.g., solar thermal power plant chimney subjected to internal and external flows) can be understood in terms of what has been presented in the fluid-conveying thin pipe system. Interestingly, however, as indicated in [132], all these mostly unexpected applications came 10-40 years after the basic research on the topic had already been done.

From the history of investigating the slender structures subjected to axial flow or axially towed in fluid, it can be seen that, various important issues, such as, but not limited to, vibrations of nanotubes conveying fluid when accounting for small-length effect, instability of pipes aspirating fluid, and nonlinear vibrations of tubular beams concurrently subjected to internal and external axial flows, remain not wholly resolved. To the authors' knowledge, several items may be of future interest on analyzing the stability and vibrations of slender structures associated with axial-flowforces.

(i) With the development of computer techniques, utilizing advanced numerical approaches to simulate the dynamical behaviour of slender structures subjected to axial flow or towed in quiescent fluid becomes realistic. Today, the simulation results may play an important role, intuitively showing the dynamical behaviour of such systems. To advance in this direction, numerical (CFD) studies using ANSYS or other procedures should be initiated, which would help reveal the dynamics closer to the truth. The CFD results may meet the requirement for better coupling between the solid and fluid models, and making fluid models more realistic.

(ii) The effect resulting from the nanoscale on the vibration of nanotubes conveying fluid has not been included so far. At small length scales the material micro-structure becomes increasingly important and its effect can no longer be ignored. Thus, the direct use of classic continuum approach to small length scales may be questionable. It is a possible solution to extend the classic continuum approach to smaller length scales by accounting for the information regarding the behavior of material microstructure. Therefore, some new theoretical models should be developed to resolve such an important issue.

(iii) In practice, the axial flow is always with stochastic velocity or has a stochastic component superposed on steady flow. Therefore, the study on stochastic dynamics of slender structures subjected to axial flow has more practical application in this area. However, the literature on this topic is quite limited.

(iv) Nonlinear problems of various slender structures discussed in Sections 2, 3, 4, 5, 6, 7, and 8 are not wholly resolved. For example, the nonlinear equation of motion of parallel-plate assembly in axial flow, slender structures axially towed in quiescent fluid, tubular beams subjected to both internal and external axial flows (may not be independent), and pipes aspirating fluid, have not been derived out, and hence the corresponding nonlinear dynamics has not been explored yet. Therefore, much attention may be concentrated on the nonlinear aspects of those slender structures mentioned in the foregoing. (v) In the past decades, various methods of vibration control mostly considered the linear equations of motion for slender structures subjected to axial flow. More importantly, in a vibration control system, time-delayed feedback unavoidably exists. As reported by $\mathrm{Xu}$ and Chung [134], time delayed feedback may change the stability and dynamics of dynamical systems, leading to much more complex dynamical behaviors. To suppress the amplified oscillations, therefore, the methods of nonlinear control for slender structures, subjected to axial flows or towed in fluid, should also be developed by considering time delayed feedback.

\section{Acknowledgment}

This work is supported by the National Natural Science Foundation of China (10772071 and 10802031) and the Scientific Research Foundation of HUST (2006Q003B).

\section{References}

[1] M. P. Païdoussis, "Flow-induced vibration in nuclear reactors and heat exchangers: practical experiences and state of knowledge," in Practical Experiences with Flow-Induced Vibrations, E. Naudascher and D. Rockwell, Eds., pp. 1-81, Springer, Berlin, Germany, 1980.

[2] J. X. Xia, J. R. Ni, and C. Mendoza, "Hydraulic lifting of manganese nodules through a riser," Journal of Offshore Mechanics and Arctic Engineering, vol. 126, no. 1, pp. 72-77, 2004.

[3] Y. A. Khulief, F. A. Al-Sulaiman, and S. Bashmal, "Vibration analysis of drillstrings with self-excited stick-slip oscillations," Journal of Sound and Vibration, vol. 299, no. 3, pp. 540-558, 2007.

[4] M. P. Païdoussis, "Dynamics of flexible slender cylinders in axial flow-part 1: theory," Journal of Fluid Mechanics, vol. 26, no. 4, pp. 717-736, 1966.

[5] M. P. Païdoussis, "Dynamics of flexible slender cylinders in axial flow-part 2: experiments," Journal of Fluid Mechanics, vol. 26, no. 4, pp. 737-751, 1966.

[6] I. A. Taleb and A. K. Misra, "Dynamics of an axially moving beam submerged in a fluid," Journal of Hydronautics, vol. 15, no. 1-4, pp. 62-66, 1981.

[7] F. Gosselin, M. P. Païdoussis, and A. K. Misra, "Stability of a deploying/extruding beam in dense fluid," Journal of Sound and Vibration, vol. 299, no. 1-2, pp. 123-142, 2007.

[8] W. Lin and N. Qiao, "Vibration and stability of an axially moving beam immersed in fluid," International Journal of Solids and Structures, vol. 45, no. 5, pp. 1445-1457, 2008.

[9] M. P. Païdoussis and N. T. Issid, "Dynamic stability of pipes conveying fluid," Journal of Sound and Vibration, vol. 33, no. 3, pp. 267-294, 1974.

[10] R. W. Gregory and M. P. Païdoussis, "Unstable oscillation of tubular cantilevers conveying fluid-I: theory," Proceedings of the Royal Society of London. Series A, vol. 293, no. 1435, pp. 512-527, 1966.

[11] G. L. Kuiper and A. V. Metrikine, "Dynamic stability of a submerged, free-hanging riser conveying fluid," Journal of Sound and Vibration, vol. 280, no. 3-5, pp. 1051-1065, 2005.

[12] G. L. Kuiper and A. V. Metrikine, "Experimental investigation of dynamic stability of a cantilever pipe aspirating fluid," Journal of Fluids and Structures, vol. 24, no. 4, pp. 541-558, 2008. 
[13] M. P. Païdoussis, "Some unresolved issues in fluid-structure interactions," Journal of Fluids and Structures, vol. 20, no. 6, pp. 871-890, 2005.

[14] M. P. Païdoussis, C. Semler, and M. Wadham-Gagnon, "A reappraisal of why aspirating pipes do not flutter at infinitesimal flow," Journal of Fluids and Structures, vol. 20, no. 1, pp. 147-156, 2005.

[15] G. T. S. Done and A. Simpson, "Dynamic stability of certain conservative and non-conservative systems," Journal of Mechanical Engineering Science, vol. 19, pp. 251-263, 1977.

[16] P. J. Holmes, "Bifurcations to divergence and flutter in flowinduced oscillations: a finite dimensional analysis," Journal of Sound and Vibration, vol. 53, no. 4, pp. 471-503, 1977.

[17] P. J. Holmes, "Pipes supported at both ends cannot flutter," Journal of Applied Mechanics, vol. 45, no. 3, pp. 619-622, 1978.

[18] P. J. Holmes and J. Marsden, "Bifurcation to divergence and flutter in flow-induced oscillations: an infinite dimensional analysis," Automatica, vol. 14, no. 4, pp. 367-384, 1978.

[19] L. Wang, "A further study on the non-linear dynamics of simply supported pipes conveying pulsating fluid," International Journal of Non-Linear Mechanics, vol. 44, no. 1, pp. 115-121, 2009.

[20] L. N. Panda and R. C. Kar, "Nonlinear dynamics of a pipe conveying pulsating fluid with parametric and internal resonances," Nonlinear Dynamics, vol. 49, no. 1-2, pp. 9-30, 2007.

[21] A. K. Bajaj, P. R. Sethna, and T. S. Lundgren, "Hopf bifurcation phenomena in tubes carrying a fluid," SIAM Journal on Applied Mathematics, vol. 39, no. 2, pp. 213-230, 1980.

[22] A. K. Bajaj and P. R. Sethna, "Effect of symmetry-breaking perturbations on flow-induced oscillations in tubes," Journal of Fluids and Structures, vol. 5, no. 6, pp. 651-679, 1991.

[23] D. M. Tang and E. H. Dowell, "Chaotic oscillations of a cantilevered pipe conveying fluid," Journal of Fluids and Structures, vol. 2, no. 3, pp. 263-283, 1988.

[24] M. P. Païdoussis and F. C. Moon, "Nonlinear and chaotic fluidelastic vibrations of a flexible pipe conveying fluid," Journal of Fluids and Structures, vol. 2, no. 6, pp. 567-591, 1988.

[25] M. P. Païdoussis, G. X. Li, and F. C. Moon, "Chaotic oscillations of the autonomous system of a constrained pipe conveying fluid," Journal of Sound and Vibration, vol. 135, no. 1, pp. 1-19, 1989.

[26] M. P. Païdoussis, G. X. Li, and R. H. Rand, "Chaotic motions of a constrained pipe conveying fluid. comparison between simulation, analysis, and experiment," Journal of Applied Mechanics, vol. 58, no. 2, pp. 559-565, 1991.

[27] M. P. Païdoussis and C. Semler, "Nonlinear and chaotic oscillations of a constrained cantilevered pipe conveying fluid: a full nonlinear analysis," Nonlinear Dynamics, vol. 4, no. 6, pp. 655-670, 1993.

[28] M. P. Païdoussis, J. P. Cusumano, and G. S. Copeland, "Lowdimensional chaos in a flexible tube conveying fluid," Journal of Applied Mechanics, vol. 59, no. 1, pp. 196-205, 1992.

[29] L. Wang and Q. Ni, "A note on the stability and chaotic motions of a restrained pipe conveying fluid," Journal of Sound and Vibration, vol. 296, no. 4-5, pp. 1079-1083, 2006.

[30] G. S. Copeland and F. C. Moon, "Chaotic flow-induced vibration of a flexible tube with end mass," Journal of Fluids and Structures, vol. 6, no. 6, pp. 705-718, 1992.
[31] M. P. Païdoussis, C. Semler, M. Wadham-Gagnon, and S. Saaid, "Dynamics of cantilevered pipes conveying fluidpart 2: dynamics of the system with intermediate spring support," Journal of Fluids and Structures, vol. 23, no. 4, pp. 569-587, 2007.

[32] Y. Modarres-Sadeghi, C. Semler, M. Wadham-Gagnon, and M. P. Païdoussis, "Dynamics of cantilevered pipes conveying fluid-part 3: three-dimensional dynamics in the presence of an end-mass," Journal of Fluids and Structures, vol. 23, no. 4, pp. 589-603, 2007.

[33] V. A. Svetlitskii, "Statics, stability and small vibrations of the flexible tubes conveying ideal incompressible fluid," Raschety na Prochnost, vol. 14, pp. 332-351, 1969.

[34] V. A. Svetlitskii, "Vibration of tubes conveying fluids," The Journal of the Acoustical Society of America, vol. 62, no. 3, pp. 595-600, 1977.

[35] V. A. Svetlitskii, Mekhanika Truboprovodov I Shlangov, Machinostronye, Moscow, Russia, 1982.

[36] S.-S. Chen, "Vibration and stability of a uniformly curved tube conveying fluid," The Journal of the Acoustical Society of America, vol. 51, no. 1B, pp. 223-232, 1972.

[37] S.-S. Chen, "Flow-induced in-plane instabilities of curved pipes," Nuclear Engineering and Design, vol. 23, no. 1, pp. 2938, 1972.

[38] S.-S. Chen, "Out-of-plane vibration and stability of curved tubes conveying fluid," Journal of Applied Mechanics, vol. 40, no. 2, pp. 362-368, 1973.

[39] R. W. Doll and C. D. Mote Jr., "The dynamic formulation and the finite element analysis of curved and twisted tubes transporting fluids," Report to the National Science Foundation, Department of Mechanical Engineering, University of California, Berkeley, Calif, USA, 1974.

[40] R. W. Doll and C. D. Mote Jr., "On the dynamic analysis of curved and twisted cylinders transporting fluids," Journal of Pressure Vessel Technology, vol. 98, no. 2, pp. 143-150, 1976.

[41] J. L. Hill and C. G. Davis, "The effect of initial forces on the hydroelastic vibration and stability of planar curved tubes," Journal of Applied Mechanics, vol. 41, no. 2, pp. 355-359, 1974.

[42] C. Dupuis and J. Rousselet, "Application of the transfer matrix method to non-conservative systems involving fluid flow in curved pipes," Journal of Sound and Vibration, vol. 98, no. 3, pp. 415-429, 1985.

[43] A. K. Misra, M. P. Païdoussis, and K. S. Van, "On the dynamics of curved pipes transporting fluid-part I: inextensible theory," Journal of Fluids and Structures, vol. 2, no. 3, pp. 221244, 1988.

[44] A. K. Misra, M. P. Païdoussis, and K. S. Van, "On the dynamics of curved pipes transporting fluid-part II: extensible theory," Journal of Fluids and Structures, vol. 2, no. 3, pp. 245261, 1988.

[45] A. K. Misra, M. P. Païdoussis, and K. S. Van, "Dynamics and stability of fluid conveying curved pipes," in Proceedings of the International Symposium on Flow-Induced Vibration and Noise, vol. 4, pp. 1-24, ASME, Chicago, Ill, USA, NovemberDecember 1988.

[46] Q. Ni, L. Wang, and Q. Qian, "Chaotic transients in a curved fluid conveying tube," Acta Mechanica Solida Sinica, vol. 18, no. 3, pp. 207-214, 2005.

[47] N. Qiao, W. Lin, and Q. Qin, "Bifurcations and chaotic motions of a curved pipe conveying fluid with nonlinear constraints," Computers and Structures, vol. 84, no. 10-11, pp. 708-717, 2006. 
[48] W. Lin, N. Qiao, and H. Yuying, "Dynamical behaviors of a fluid-conveying curved pipe subjected to motion constraints and harmonic excitation," Journal of Sound and Vibration, vol. 306, no. 3-5, pp. 955-967, 2007.

[49] D. Jung and J. Chung, "In-plane and out-of-plane motions of an extensible semi-circular pipe conveying fluid," Journal of Sound and Vibration, vol. 311, no. 1-2, pp. 408-420, 2008.

[50] Y. Huang, G. Zeng, and F. Wei, "A new matrix method for solving vibration and stability of curved pipes conveying fluid," Journal of Sound and Vibration, vol. 251, no. 2, pp. 215-225, 2002.

[51] Q. Ni and Y. Huang, "Differential quadrature method to stability analysis of pipes conveying fluid with spring support," Acta Mechanica Solida Sinica, vol. 13, no. 4, pp. 320-327, 2000.

[52] W. Lin and N. Qiao, "In-plane vibration analyses of curved pipes conveying fluid using the generalized differential quadrature rule," Computers and Structures, vol. 86, no. 1-2, pp. 133-139, 2008.

[53] C. Dupuis and J. Rousselet, "The equations of motion of curved pipes conveying fluid," Journal of Sound and Vibration, vol. 153, no. 3, pp. 473-489, 1992.

[54] S. Iijima, "Helical microtubules of graphitic carbon," Nature, vol. 354, no. 6348, pp. 56-58, 1991.

[55] R. F. Gibson, E. O. Ayorinde, and Y.-F. Wen, "Vibrations of carbon nanotubes and their composites: a review," Composites Science and Technology, vol. 67, no. 1, pp. 1-28, 2007.

[56] G. Hummer, J. C. Rasaiah, and J. P. Noworyta, "Water conduction through the hydrophobic channel of a carbon nanotube," Nature, vol. 414, no. 6860, pp. 188-190, 2001.

[57] A. Karlsson, R. Karlsson, M. Karlsson, et al., "Molecular engineering: networks of nanotubes and containers," Nature, vol. 409, no. 6817, pp. 150-152, 2001.

[58] Y. Gao and Y. Bando, "Carbon nanothermometer containing gallium,” Nature, vol. 415, no. 6872, p. 599, 2002.

[59] Z. Mao and S. B. Sinnott, "A computational study of molecular diffusion and dynamic flow through carbon nanotubes," The Journal of Physical Chemistry B, vol. 104, no. 19, pp. 4618-4624, 2000.

[60] Y. Gogotsi, J. A. Libera, A. Güvenç-Yazicioglu, and C. M. Megaridis, "In situ multiphase fluid experiments in hydrothermal carbon nanotubes," Applied Physics Letters, vol. 79, no. 7, pp. 1021-1023, 2001.

[61] V. P. Sokhan, D. Nicholson, and N. Quirke, "Fluid flow in nanopores: accurate boundary conditions for carbon nanotubes," The Journal of Chemical Physics, vol. 117, no. 18, pp. 8531-8539, 2002.

[62] Y. Liu, Q. Wang, T. Wu, and L. Zhang, "Fluid structure and transport properties of water inside carbon nanotubes," The Journal of Chemical Physics, vol. 123, no. 23, Article ID 234701, 7 pages, 2005.

[63] R. E. Tuzun, D. W. Noid, B. G. Sumpter, and R. C. Merkle, "Dynamics of fluid flow inside carbon nanotubes," Nanotechnology, vol. 7, no. 3, pp. 241-246, 1996.

[64] T. Natsuki, Q.-Q. Ni, and M. Endo, "Wave propagation in single- and double-walled carbon nanotubes filled with fluids," Journal of Applied Physics, vol. 101, no. 3, Article ID 034319, 5 pages, 2007.

[65] J. Yoon, C. Q. Ru, and A. Mioduchowski, "Vibration and instability of carbon nanotubes conveying fluid," Composites Science and Technology, vol. 65, no. 9, pp. 1326-1336, 2005.

[66] J. Yoon, C. Q. Ru, and A. Mioduchowski, "Flow-induced flutter instability of cantilever carbon nanotubes," International
Journal of Solids and Structures, vol. 43, no. 11-12, pp. 33373349, 2006.

[67] C. D. Reddy, C. Lu, S. Rajendran, and K. M. Liew, "Free vibration analysis of fluid-conveying single-walled carbon nanotubes," Applied Physics Letters, vol. 90, no. 13, Article ID 133122, 3 pages, 2007.

[68] X. Wang, X. Y. Wang, and G. G. Sheng, "The coupling vibration of fluid-filled carbon nanotubes," Journal of Physics D, vol. 40, no. 8, pp. 2563-2572, 2007.

[69] L. Wang and Q. Ni, "On vibration and instability of carbon nanotubes conveying fluid," Computational Materials Science, vol. 43, no. 2, pp. 399-402, 2008.

[70] L. Wang, Q. Ni, M. Li, and Q. Qian, "The thermal effect on vibration and instability of carbon nanotubes conveying fluid," Physica E, vol. 40, no. 10, pp. 3179-3182, 2008.

[71] Y. Yan, W. Q. Wang, and L. X. Zhang, "Dynamical behaviors of fluid-conveyed multi-walled carbon nanotubes," Applied Mathematical Modelling, vol. 33, no. 3, pp. 1430-1440, 2009.

[72] L. Wang, Q. Ni, and M. Li, "Buckling instability of doublewall carbon nanotubes conveying fluid," Computational Materials Science, vol. 44, no. 2, pp. 821-825, 2008.

[73] Y. Yan, X. Q. He, L. X. Zhang, and C. M. Wang, "Dynamic behavior of triple-walled carbon nanotubes conveying fluid," Journal of Sound and Vibration, vol. 319, no. 3-5, pp. 10031018, 2009.

[74] K. Dong, B. Y. Liu, and X. Wang, "Wave propagation in fluidfilled multi-walled carbon nanotubes embedded in elastic matrix," Computational Materials Science, vol. 42, no. 1, pp. 139-148, 2008.

[75] J. P. Den Hartog, "John Orr memorial lecture: recent cases of mechanical vibration," The South African Mechanical Engineer, vol. 19, no. 3, pp. 53-68, 1969.

[76] J. J. Bailey and I. Finnie, "An analytical study of drillstring vibration," Journal of Engineering for Industry, vol. 82, no. 2, pp. 122-128, 1960.

[77] R. W. Tucker and C. Wang, "An integrated model for drillstring dynamics," Journal of Sound and Vibration, vol. 224, no. 1, pp. 123-165, 1999.

[78] F. Cesari and S. Curioni, "Buckling instability in tubes subject to internal and external axial fluid flow," in Proceedings of the 4th Conference on Dimensioning, pp. 301-311, Hungarian Academy of Science, Budapest, Hungary, October 1971.

[79] M. J. Hannoyer and M. P. Païdoussis, "Instabilities of tubular beams simultaneously subjected to internal and external axial flows," Journal of Mechanical Design, vol. 100, pp. 328-336, 1978.

[80] J. V. Grigoriev, "Stability of a drill tube column with an initial curvature in the axial stream," Journal of Bauman Moscow State Technical University: Mashinostronye, vol. 5, pp. 23-28, 1978 (Russian).

[81] M. P. Païdoussis and P. Besancon, "Dynamics of arrays of cylinders with internal and external axial flow," Journal of Sound and Vibration, vol. 76, no. 3, pp. 361-379, 1981.

[82] X. Wang and F. Bloom, "Dynamics of a submerged and inclined concentric pipe system with internal and external flows," Journal of Fluids and Structures, vol. 13, no. 4, pp. 443460, 1999.

[83] M. P. Païdoussis, T. P. Luu, and S. Prabhakar, "Dynamics of a long tubular cantilever conveying fluid downwards, which then flows upwards around the cantilever as a confined annular flow," Journal of Fluids and Structures, vol. 24, no. 1, pp. 111-128, 2008. 
[84] T. P. Luu, On the dynamics of three systems involving tubular beams conveying fluid, M.Eng. thesis, Department of Mechanical Engineering, McGill University, Montreal, Canada, 1983.

[85] M. P. Païdoussis and J.-P. Denise, "Flutter of cylindrical shells conveying fluid," Journal of Sound and Vibration, vol. 16, pp. 456-461, 1971.

[86] M. P. Païdoussis and J.-P. Denise, "Flutter of thin cylindrical shells conveying fluid," Journal of Sound and Vibration, vol. 20, no. 1, pp. 9-26, 1972.

[87] V. B. Nguyen, M. P. Païdoussis, and A. K. Misra, "An experimental study of the stability of cantilevered coaxial cylindrical shells conveying fluid," Journal of Fluids and Structures, vol. 7, no. 8, pp. 913-930, 1993.

[88] A. El Chebair, M. P. Païdoussis, and A. K. Misra, "Experimental study of annular flow-induced instabilities of cylindrical shells," Journal of Fluids and Structures, vol. 3, no. 4, pp. 349364, 1989.

[89] K. N. Karagiozis, M. P. Païdoussis, A. K. Misra, and E. Grinevich, "An experimental study of the nonlinear dynamics of cylindrical shells with clamped ends subjected to axial flow," Journal of Fluids and Structures, vol. 20, no. 6, pp. 801816, 2005.

[90] K. N. Karagiozis, M. P. Païdoussis, M. Amabili, and A. K. Misra, "Nonlinear stability of cylindrical shells subjected to axial flow: theory and experiments," Journal of Sound and Vibration, vol. 309, no. 3-5, pp. 637-676, 2008.

[91] K. N. Karagiozis, M. P. Païdoussis, and A. K. Misra, "Transmural pressure effects on the stability of clamped cylindrical shells subjected to internal fluid flow: theory and experiments," International Journal of Non-Linear Mechanics, vol. 42, no. 1, pp. 13-23, 2007.

[92] K. N. Karagiozis, M. P. Païdoussis, E. Grinevich, A. K. Misra, and M. Amabili, "Stability and nonlinear dynamics of clamped circular cylindrical shells in contact with flowing fluid," in Proceedings of IUTAM Symposium on Integrated Modeling of Fully Coupled Fluid Structure Interactions Using Analysis, Computations and Experiments, pp. 375-390, Kluwer Academic Publishers, New Brunswick, NJ, USA, June 2003.

[93] M. Amabili, F. Pellicano, and M. P. Païdoussis, "Nonlinear dynamics and stability of circular cylindrical shells containing flowing fluid-I: stability," Journal of Sound and Vibration, vol. 225, no. 4, pp. 655-699, 1999.

[94] Y. Watanabe, S. Suzuki, M. Sugihara, and Y. Sueoka, "An experimental study of paper flutter," Journal of Fluids and Structures, vol. 16, no. 4, pp. 529-542, 2002.

[95] C. Lemaitre, P. Hémon, and E. de Langre, "Instability of a long ribbon hanging in axial air flow," Journal of Fluids and Structures, vol. 20, no. 7, pp. 913-925, 2005.

[96] A. Kornecki, E. H. Dowell, and J. O’Brien, “On the aeroelastic instability of two-dimensional panels in uniform incompressible flow," Journal of Sound and Vibration, vol. 47, no. 2, pp. 163-178, 1976.

[97] J. Dugundji, E. H. Dowell, and B. Perkins, "Subsonic flutter of panels on continuous elastic foundations," AIAA Journal, vol. 1, no. 5, pp. 1146-1154, 1963.

[98] T. Ishii, "Aeroelastic instabilities of simply supported panels in subsonic flow," in American Institute of Aeronautics and Astronautics, Royal Aeronautical Society, and Japan Society for Aeronautical and Space Sciences, Aircraft Design and Technology Meeting, Los Angeles, Calif, USA, November 1965, Paper 65-772.
[99] D. S. Weaver and T. E. Unny, "Hydroelastic stability of a flat plate," Journal of Applied Mechanics, vol. 37, no. 3, pp. 823827, 1970.

[100] C. H. Ellen, "Stability of simply supported rectangular surfaces in uniform subsonic flow," Journal of Applied Mechanics, vol. 40 , no. 1 , pp. $68-72,1973$.

[101] L. Tang and M. P. Païdoussis, "On the instability and the postcritical behaviour of two-dimensional cantilevered flexible plates in axial flow," Journal of Sound and Vibration, vol. 305, no. 1-2, pp. 97-115, 2007.

[102] L. Tang and M. P. Païdoussis, "The influence of the wake on the stability of cantilevered flexible plates in axial flow," Journal of Sound and Vibration, vol. 310, no. 3, pp. 512-526, 2008.

[103] L. Tang and M. P. Paidoussis, "The dynamics of twodimensional cantilevered plates with an additional spring support in axial flow," Nonlinear Dynamics, vol. 51, no. 3, pp. 429-438, 2008.

[104] W. K. Doan, "The engineering test reactor-a status report," Nucleonics, vol. 16, no. 1, pp. 102-105, 1958.

[105] W. L. Zabriskie, "An experimental evaluation of the effect of length-to-width ratio on the critical flow velocity of single plate assemblies," Tech. Rep. 59GL209, General Electric Company, General Engineering Laboratory, Schenectady, NY, USA, 1959.

[106] R. D. Groninger and J. J. Kane, "Flow induced deflections of parallel flat plates," Nuclear Science and Engineering, vol. 16, pp. 218-226, 1963.

[107] G. E. Smissaert, "Static and dynamic hydro-elastic instabilities in MTR-type fuel elements-part I: introduction and experimental investigation," Nuclear Engineering and Design, vol. 7, no. 6, pp. 535-546, 1968.

[108] D. R. Miller, "Critical flow velocities for collapse of reactor parallel-plate fuel assemblies," Journal of Engineering for Power, vol. 82, pp. 83-95, 1960.

[109] R. B. Johansson, "Hydraulic instability of reactor parallel plate fuel assemblies," in Nuclear Engineering Science Conference, New York, NY, USA, April 1960, preprint paper no. 57.

[110] R. J. Scavuzzo, "Hydraulic instability of flat parallel-plate assemblies," Nuclear Science and Engineering, vol. 21, pp. 463-472, 1965.

[111] M. W. Wambsganss Jr., "Second-order effects as related to critical coolant flow velocities and reactor parallel plate fuel assemblies," Nuclear Engineering and Design, vol. 5, no. 3, pp. 268-276, 1967.

[112] G. S. Rosenberg and C. K. Youngdahl, "A simplified dynamic model for the vibration frequencies and critical coolant flow velocities for reactor parallel plate fuel assemblies," Nuclear Science and Engineering, vol. 13, pp. 91-102, 1962.

[113] Y.-R. Yang and J.-Y. Zhang, "Frequency analysis of a parallel flat plate-type structure in still water-part I: a multi-span beam," Journal of Sound and Vibration, vol. 203, no. 5, pp. 795-804, 1997.

[114] Y.-R. Yang and J.-Y. Zhang, "Frequency analysis of a parallel flat plate-type structure in still water-part II: a complex structure," Journal of Sound and Vibration, vol. 203, no. 5, pp. 805-814, 1997.

[115] C. Q. Guo and M. P. Païdoussis, "Analysis of hydroelastic instabilities of rectangular parallel-plate assemblies," Journal of Pressure Vessel Technology, vol. 122, no. 4, pp. 171-176, 2000.

[116] M. P. Païdoussis, "The amplitude of fluid-induced vibration of cylinders in axial flow," Tech. Rep. AECL-2225, Atomic Energy of Canada, Ontario, Canada, 1965. 
[117] M. P. Païdoussis, "An experimental study of vibration of flexible cylinders induced by nominally axial flow," Nuclear Science and Engineering, vol. 35, pp. 127-138, 1969.

[118] M. P. Païdoussis, "Vibrations of cylindrical structures subjected to axial flow," Journal of Engineering for Industry, vol. 96, pp. 547-552, 1974.

[119] M. P. Païdoussis, "Dynamics of cylindrical structures subjected to axial flow," Journal of Sound and Vibration, vol. 29, no. 3, pp. 365-385, 1973.

[120] W. R. Hawthorne, "The early development of the Dracone flexible barge," Proceedings of the Institution of Mechanical Engineers, vol. 175, pp. 52-83, 1961.

[121] M. P. Païdoussis, "Dynamics of flexible slender cylinders in axial flow-part 2: experiments," Journal of Fluid Mechanics, vol. 26, no. 4, pp. 737-751, 1966.

[122] Y. Modarres-Sadeghi, M. P. Païdoussis, and C. Semler, "A nonlinear model for an extensible slender flexible cylinder subjected to axial flow," Journal of Fluids and Structures, vol. 21, no. 5-7, pp. 609-627, 2005.

[123] Y. Modarres-Sadeghi, M. P. Païdoussis, C. Semler, and E. Grinevich, "Experiments on vertical slender flexible cylinders clamped at both ends and subjected to axial flow," Philosophical Transactions of the Royal Society A, vol. 366, no. 1868, pp. 1275-1296, 2008.

[124] M. P. Païdoussis, E. Grinevich, D. Adamovic, and C. Semler, "Linear and nonlinear dynamics of cantilevered cylinders in axial flow-part 1: physical dynamics," Journal of Fluids and Structures, vol. 16, no. 6, pp. 691-713, 2002.

[125] C. Semler, J. L. Lopes, N. Augu, and M. P. Païdoussis, "Linear and nonlinear dynamics of cantilevered cylinders in axial flow-part 3: nonlinear dynamics," Journal of Fluids and Structures, vol. 16, no. 6, pp. 739-759, 2002.

[126] M. P. Païdoussis, "The dynamics of clusters of flexible cylinders in axial flow: theory and experiments," Journal of Sound and Vibration, vol. 65, no. 3, pp. 391-417, 1979.

[127] S. S. Chen, Flow-Induced Vibration of Circular Structures, Hemisphere, Washington, DC, USA, 1987.

[128] M. P. Païdoussis, "Stability of towed, totally submerged flexible cylinders," Journal of Fluid Mechanics, vol. 34, no. 2, pp. 273-297, 1968.

[129] A. P. Dowling, "The dynamics of towed flexible cylinderspart 1: neutrally buoyant elements," Journal of Fluid Mechanics, vol. 187, pp. 507-532, 1988.

[130] E. de Langre, M. P. Païdoussis, O. Doaré, and Y. ModarresSadeghi, "Flutter of long flexible cylinders in axial flow," Journal of Fluid Mechanics, vol. 571, pp. 371-389, 2007.

[131] O. Becker, "Das durchströmte Rohr-Literaturbericht," Tech. Rep. IHZ-M80-212, der Ingenieurhochschule Zittau, Zittau, Germany, 1981.

[132] M. P. Païdoussis and G. X. Li, "Pipes conveying fluid: a model dynamical problem," Journal of Fluids and Structures, vol. 7, no. 2, pp. 137-204, 1993.

[133] M. P. Païdoussis, Fluid-Structure Interactions: Slender Structures and Axial Flow. Volume 2, Academic Press, London, UK, 2004.

[134] J. Xu and K. W. Chung, "Effects of time delayed position feedback on a van der Pol-Duffing oscillator," Physica D, vol. 180, no. 1-2, pp. 17-39, 2003. 

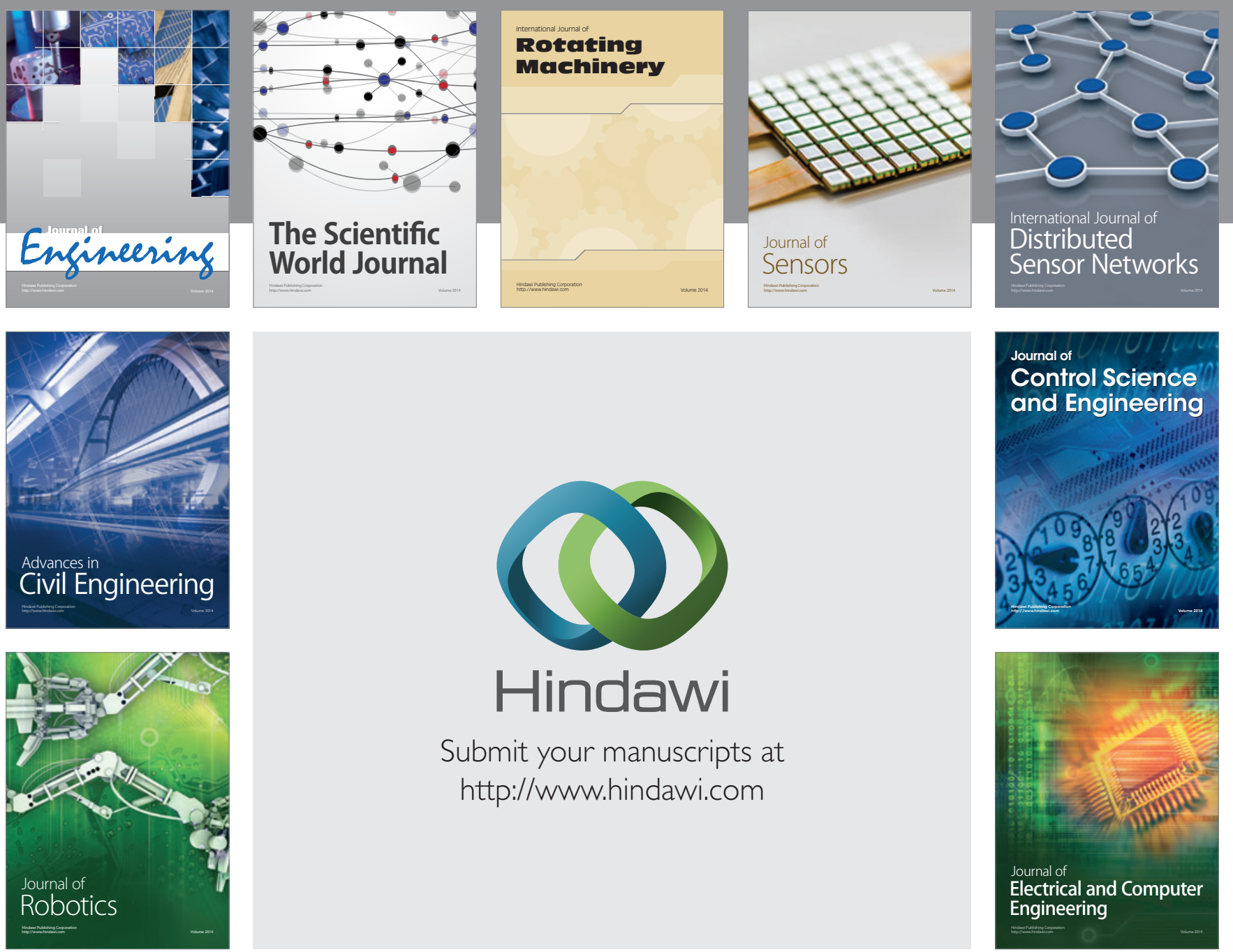

Submit your manuscripts at

http://www.hindawi.com
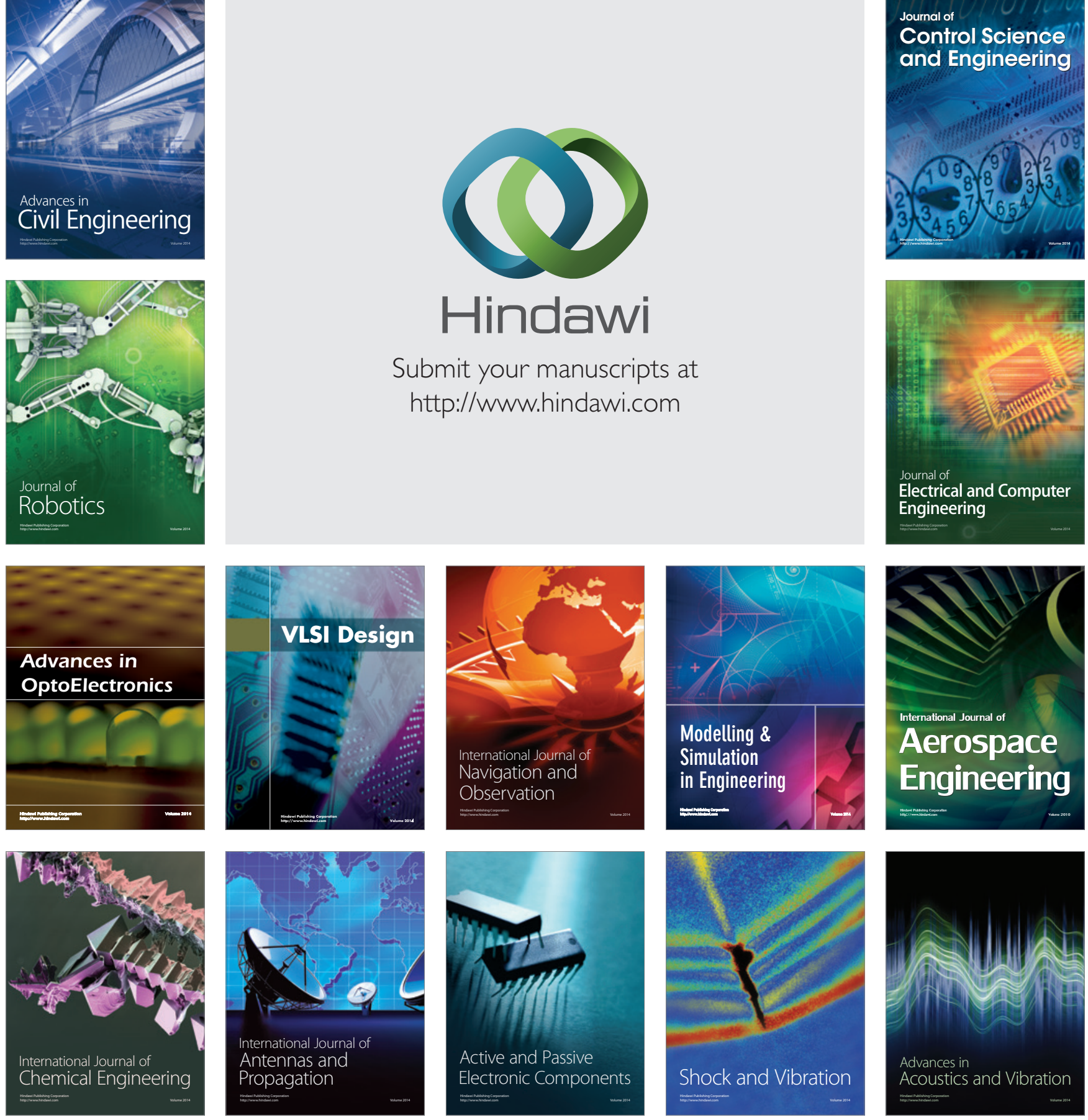